IZA DP No. 6114

The Implications of Cultural Background on Labour Market Choices: The Case of Religion and Entrepreneurship

Luca Nunziata

Lorenzo Rocco

November 2011 


\title{
The Implications of Cultural Background on Labour Market Choices: The Case of Religion and Entrepreneurship
}

\author{
Luca Nunziata \\ University of Padua \\ and IZA
}

Lorenzo Rocco

University of Padua

Discussion Paper No. 6114

November 2011

\author{
IZA \\ P.O. Box 7240 \\ 53072 Bonn \\ Germany \\ Phone: +49-228-3894-0 \\ Fax: +49-228-3894-180 \\ E-mail: iza@iza.org
}

\begin{abstract}
Any opinions expressed here are those of the author(s) and not those of IZA. Research published in this series may include views on policy, but the institute itself takes no institutional policy positions.

The Institute for the Study of Labor (IZA) in Bonn is a local and virtual international research center and a place of communication between science, politics and business. IZA is an independent nonprofit organization supported by Deutsche Post Foundation. The center is associated with the University of Bonn and offers a stimulating research environment through its international network, workshops and conferences, data service, project support, research visits and doctoral program. IZA engages in (i) original and internationally competitive research in all fields of labor economics, (ii) development of policy concepts, and (iii) dissemination of research results and concepts to the interested public.
\end{abstract}

IZA Discussion Papers often represent preliminary work and are circulated to encourage discussion. Citation of such a paper should account for its provisional character. A revised version may be available directly from the author. 
IZA Discussion Paper No. 6114

November 2011

\section{ABSTRACT}

\section{The Implications of Cultural Background on Labour Market Choices: The Case of Religion and Entrepreneurship}

We suggest a methodology for identifying the implications of alternative cultural and social norms embodied by religious denomination on labour market outcomes, by estimating the differential impact of Protestantism versus Catholicism on the propensity to be an entrepreneur, on the basis of the diverse minority status of both confessions across European regions. Our quasi-experimental research design exploits the stronger degree of attachment to religious ethic of religious minorities and the exogenous historical determination of the geographical distribution of religious minorities in Europe. Our analysis of European Social Survey data collected in four waves between 2002 and 2008 in 22 European countries, indicates that cultural background has a significant effect on the individual propensity to become an entrepreneur, with Protestantism increasing the chances to be an entrepreneur by around 3\% with respect to Catholicism. Our findings, stable across a number of robustness checks, provide further evidence on the need to take cultural elements into consideration when analysing economic behaviour.

JEL Classification: J24, J21, Z12, Z13

Keywords: entrepreneurship, self-employment, religion, culture, Protestantism, Catholicism

Corresponding author:

Luca Nunziata

University of Padua

Via del Santo 33

35121, Padua

Italy

E-mail: luca.nunziata@unipd.it 


\section{Introduction}

This paper investigates the implications of culture in terms of economic outcomes through the examination of the relationship between specific cultural norms embodied by religious denominations and the choice of becoming an entrepreneur. In other words, our question is whether the peculiar characteristics of a successful entrepreneur ${ }^{3}$, such as intuition, courage, self-control, leadership, propensity to invest, are favoured or not by a given cultural and ethical background embodied by religious denominations.

In our analysis the word "culture" refers to religious culture, i.e. that inextricable combination of specific beliefs, traditions, ethical principles, sense of the good and the evil, which differentiate a religion and creates its own identity. The hypothesis we aim at testing is whether religious individuals may be subject, whether consciously or not, to a different set of constraints when taking decisions about their life and work career.

In this respect, the choice of being an entrepreneur seems to be a natural outcome to be affected by cultural constraints because of the peculiarities of self-employment when compared to dependent employment. Blanchflower and Oswald (1998) show for example how the self-employed are generally more satisfied with their job than dependent employees, despite being subject to higher levels of stress. The trade-off between satisfaction and stress is potentially mediated on the values embodied by cultural background. In addition, this particular choice is indeed revealing as regards the real attitudes of individuals versus wealth accumulation and ambition of success.

Entrepreneurs may indeed be considered the key players of a market economy, for they embody the principles of capitalism and their seek of success stimulates innovation. Given the economic relevance of this figure, understanding the implications of a cultural background on the choice of becoming an entrepreneur seems to be a good test of whether there exists a causal effect of culture on economic behavior at all.

3 In what follows we will use the words entrepreneurs and self-employed interchangeably. 
In this respect, Europe represents a unique economic environment where to analyze the implications of religious denomination on the propensity of being an entrepreneur. In the first place, Europe is characterized by a relatively homogeneous economic environment, if compared to other areas of the world, and by a relevant proportion of entrepreneurs among employed individuals. Moreover, and most importantly, European religious denominations are mainly Christian, with two variants represented by Catholicism and Protestantism. Religious denominations are scattered across European regions, generating large variations in the proportion of Catholics and Protestants, whereas the overall economic and social environment varies only to a certain extent. Religious individuals are therefore quite similar on average as regards the economic environment they face and their general beliefs. However, Catholic and Protestant ethic differ on some important specific aspects. Two relevant differences regard the questions of predestination and unmediated relation with God.

Protestantism, and especially its Calvinist branch, maintains that God decides (or is aware of) who is to be elected or damned since the beginnings. Individuals ignore their own fate, but only the elected have the capacity to increase God's glory during their life by means of their good works. Therefore achieving success in the worldly life, which is the precondition for good works to be possible, is a clear symptom of election. This view puts success in economic competition, material achievements and wealth accumulation, under a new light: rather than being considered sources of temptation and possible idolatry, or the outcome of the exploitation of the weak perpetrated by the strong, they witness the state of grace to both the individual and the community. In this new perspective, the typical purposes of capitalism are not only acceptable, but even morally desirable. Nonetheless, asceticism must inspire everyday life, as wealth has to be used for good works and to the benefit of the community and not for the seek of personal pleasure.

Quite at the opposite, Catholicism is historically rather cold if not hostile towards worldly success and competition. It emphasizes poverty and an isolated monastic life as the main avenue to achieve salvation. It reassures the poor and the weak, promising them eternal salvation, while the rich and the powerful will be punished for their sins. 
According to the Protestant ethic there is no need for intermediation between God and the human being, nor sacraments and confession have any significance, because everybody's state of grace is predetermined. Instead, Protestants are encouraged to focus on selfreflection as the path towards God is a personal one. This conception strengthens individualism and self-confidence, two important personal characteristics in a capitalistic economy.

Symmetrically, Catholicism emphasizes the role of the priest as mediator between God and men, and the only allowed to administer the sacraments required for keeping or restoring the link with God. Much emphasis is also put on the need of a unique and standardized reading of the Scriptures, and personal interpretations are refused.

In his classic contribution, The Protestant Ethic and the Spirit of Capitalism, Max Weber (1904) argued that these specificities of Protestantism were crucial in inducing many individuals in pre-capitalistic societies to engage in secular activities. The spirit of capitalism, which in Weber's work may be defined as the rational pursuit of economic profit and the morality attached to this scope, is fundamentally embodied by the attitude towards entrepreneurship activities. Weber's theory is still to this day an important reference point for contemporary research on this topic. In a recent contribution, Becker and Woessmann (2009) dispute Weber's original stand, arguing that the prosperity of Protestant economies was mainly due to the generation of human capital induced by the Protestant instruction in reading the Bible, rather than to the peculiarities of Protestant ethic.

In what follows, we do not directly test Weber's original theory, since we do not investigate the historical process leading to the development of capitalism in Europe. We do however provide an empirical investigation on the cultural determinants of economic behavior in contemporary economies. More specifically, we adopt a quasi-experimental research design in order to investigate the relationship between culture and economic outcomes by exploiting the specificity of religious patterns in European regions. Our emphasis is on carefully designing an identification strategy which may enable us to assess whether there exists a causal link from religious norms to economic outcomes, rather than identifying which is the value-related channel that operates in this direction. 
In a spirit similar to Gruber (2005), we focus on the structure of the geographical distributions of religious creeds across Europe by looking at the minoritarian/majoritarian nature of Protestantism and Catholicism in each European region. This distribution is mainly inherited from deep historical processes, which may be safely considered exogenous to individual labour market choices in current times.

The idea is that individuals belonging to minority creeds, have on average deeper adherence to the bound of social and ethical norms carried by their religion, with respect to individuals belonging to majority creeds. This does not mean that majority religious individuals cannot individually personify their own religion's values, but only that concentrating on minority individuals, or more specifically on the differential impact of different minority religion creeds, we are more likely to identify the effect of religious ethic on economic outcomes.

Using European Social Survey (ESS) data collected every two years from 2002 to 2008 in 22 European countries, our empirical strategy aims at capturing the differential impact of Protestant versus Catholic "ethics" net of all confounders related to the minority status of each religious denomination across European regions, and including a large set of controls at the individual as well as at the regional level. Most importantly, ESS data also include information about parents' occupation. This is a crucial bit of information, as being raised in a family of entrepreneurs is a strong predictor of the propensity of becoming an entrepreneur.

According to our empirical findings, Protestantism does indeed favor entrepreneurship. Our key result is that Protestants are around 3 percentage points more likely to be entrepreneurs than Catholics, after controlling for individual, family background, regional characteristics and country or regional fixed effects. The latter fully capture common national/regional cultural traits, in addition to the extent to which legislation and fiscal policy favors entrepreneurship, and the national/regional entrepreneurial propensity.

The paper is organised as follows. Section 2 discusses the relationship between religion and entrepreneurship. Section 3 presents our identification strategy and tests its tenets while section 4 introduces the model. Data are presented in Section 5 and the estimation results in 
Section 6. The validity and robustness of our findings are further discussed in detail in Section 7. Section 8 finally concludes.

\section{Culture and religion as economic factors.}

Guiso et al. (2006) provide a general introduction to the role of cultural traits in the economy and make a distinction between a slow-moving component of culture transmitted "fairly unchanged from generation to generation", and a fast-moving component which may be illustrated by peer-group effects. An example of the former could be represented by religious beliefs. According to the authors, a cultural tradition may be the result of an optimization process at societal level, but the cultural elements inherited by each individual are unaffected by individual experiences during their lifetime.

Tabellini (2005) provides some empirical evidence on the effects of culture on economic outcomes, by measuring values and beliefs (such as trust, respect for others, confidence in self-determination) at the regional level in Europe, and instrumenting them with a set of historical variables. As a result the exogenous regional component of culture is found to be correlated with current economic development.

More recently, Giavazzi et al. (2009) focus on the role played by cultural attitudes towards gender, the young and leisure, by showing how these can explain women and young employment dynamics, as well as total hours worked in OECD countries.

Guiso et al. (2009) show instead how trust of European citizens towards other countries, rooted in culture, can explain trade and foreign investment patterns. Under the Guiso et al. framework the link goes from culture (deep) to beliefs and values, and from beliefs and values to economic outcomes.

The strand of economic research on religion has been inaugurated by Iannacone (1988). He views religious norms as endogenously produced by optimization at group-level. Thereafter, an increasing interest was devoted to the role and the mechanism of religion, both from a 
theoretical (e.g. Benabou and Tirole, 2006) and an empirical perspective (Gruber and Hungerman, 2008, and Becker and Woessmann, 2009, discussed below, among others).

However, the link between religion and the choice of becoming an entrepreneur has not been previously empirically investigated except for few papers, none of which adopts a quasi-experimental approach and focus on the specificities of Europe. Audretsch et al. (2007) find that in India Islam and Christianity favors entrepreneurship, while Hinduism inhibits it. Minns and Rizov (2005) study entrepreneurship in Canada at the beginning of the 20th Century and find that Catholics were less likely to become entrepreneurs than Protestants. Guiso et al. (2007) conclude that "Buddhism and Christianity seem most conducive to capitalism, and Islam the least".

In the business literature there are several qualitative contributions. A detailed survey is offered by Dana (2009), where, among other things, examples of financial, employment and information networks that emerge between people of the same religion are presented. Carswell and Rolland (2004) question whether the positive effect of Protestant work ethic on entrepreneurship could be negatively affected by the increasing ethnic and religious diversity associated to migration.

In a recent paper Falck and Woessmann (2010) analyze the effect of competition between public and private schools in Europe on the propensity to become entrepreneurs among students aged 15. Competition is measured by the proportion of students enrolled in private schools. As this variable is likely to be endogenous, it is instrumented by the proportion of Catholics at the end of the Nineteen Century in the countries where Catholicism was not the state religion. At that time the state monopoly on education was strongly opposed by Catholics, who promoted private confessional schools. The authors find that school competition favors entrepreneurship and that competition is higher among Central and Northern Europe countries where Catholicism was not a state religion but where large Catholic communities resided. The authors do not focus on the ethical content of alternative religious denominations, but rather argue that the school competition emerged from the struggle between laic and confessional education favored entrepreneurship. 
In what follows we take a different perspective, mainly driving our attention to the cultural differences between Protestantism and Catholicism, and their effect on entrepreneurship.

\section{Research Design}

Cultural background is hard to define and measure, and sometimes it is arduous to disentangle cultural elements from correlated third factors simultaneously shaping individual attitudes or the environment where individuals act. For instance, Becker and Woessmann (2009) argue that Protestantism, thanks to its emphasis on the personal reading of the Bible, encouraged education since reformation. According to this view, it is education and not the protestant ethic, like in Weber's theory, which created the humus for the higher prosperity of reformed areas in Germany in the late 1800s. Their view is therefore alternative to Max Weber's theory of a direct role of Protestant ethic in explaining the development of early capitalism or more generally economic progress in Germany.

In what follows, we do not investigate whether religion denomination has a general effect on economic prosperity, but we rather focus on a specific dimension of economic activity, i.e. entrepreneurship, which is left aside from Becker and Woessmann's analysis but can be associated with Weber's thesis. Our aim is to test whether the social norms attached to a Protestant versus Catholic background affect the individual choice of becoming an entrepreneur in a modern economy, controlling for individual educational attainment. In principle, this could provide a further test of an education-based versus an ethics-based effect of Protestantism on economic outcomes. However, we should keep in mind that one does not exclude the other. In other words, Weber's theory may fail to identify the major driving force behind the early development of capitalism, but still give us some indications on how culture affect economic choices in a mature market economy.

In order to investigate the existence of a causal relationship between the cultural elements embodied by religion and a specific outcome of interest, the identification strategy should deal with the confounding factors that may corrupt our interpretation of the empirical evidence. Europe is an ideal setting to construct such an analysis, being characterized by well established regional religious traditions, mostly related to Christianity but that still differ in a 
number of ways as regards basic ethical principles and prescriptions. Protestantism and Catholicism are indeed distinct confessions of the same religion, Christianity, and they share a large part of their beliefs and values, while differing only with respect to certain peculiar cultural aspects that we aim at capturing through our empirical modelling. In addition, European Catholics and Protestants operate in similar economic contexts, they share a similar access to education, which is guaranteed regardless of individual religion, and share similar languages (in same cases identical, such as in the Netherlands, Germany and the UK) and other cultural dimensions. There is no negative discrimination on the labor market that could lead to entrepreneurship as a sort of obliged way (Clark and Drinkwater, 2000). Therefore Protestants and Catholics are on average homogenous in terms of what matters to entrepreneurship, except for their specific religious culture.

A major issue, however, when dealing with the ethical and cultural content of religions is that self-identification with a certain religious creed does not necessarily imply internalization of religious ethical principles. This is the reason why various religiousness intensity indicators have been used before in order to measure the different degree of attachment of individuals to religious cultural beliefs (McCleary and Barro, 2006). Nevertheless, most of these indicators, e.g. frequency of attendance of religious services, weekly prayers, donation of money and time to religious organizations, are likely to be endogenous to labour market choices. We should instead use a religious intensity measure which is exogenous to our outcome of interest.

We therefore develop a research strategy that aims at addressing the issues discussed above, focusing on the two main Christian denominations, i.e. Protestantism and Catholicism. Our identification strategy rests on four pillars that attains, respectively, to: (1) how individuals choose to adhere to a certain religious denomination, (2) the rationale of the geographical distribution of religious denominations across European regions, (3) the degree of adherence to the norms and ethic embodied by a religious denomination and (4) possible confounding factors given pillars 1 to 3 .

As regards the first point, we think about religion as being learnt at home, i.e. being transmitted from parents to sons. People can turn atheist when they are raised religious, but 
typically they do not switch from their parents' confession to a different confession, as confirmed by simple data inspection. Therefore we can assume that the only individual choice regarding religion is whether to be religious or atheist. When individuals decide to be religious, they adopt their parents' confession.

Second, the geographical distribution of religion in Europe is historically determined. The presence of Protestant and Catholic minorities closely follows the equilibrium found at the end of the religion wars of Sixteen and Seventeen Centuries. This distribution is persistent due to the inter-generational transmission of religion. Therefore, the current status of being part of a religious minority can be considered as exogenously given.

Third, the followers of religious minorities accept and internalize to a higher degree the ethical norms of their religion and the broader culture a religion carries on. This is because the clergy of a minority religion provides higher effort to maintain its followers and possibly attract new ones, and because of the willingness of minorities to defend their own identity. In general, being part of a minority is more costly and therefore it can only be justified if the attachment to a faith is stronger. Minorities are therefore composed of more orthodox and stricter believers than majorities.

Fourth, the condition of being minority might carry out other characteristics or endowments than stricter adhesion to a religious culture. More specifically, minorities can enjoy stricter and more intense social networks which could be much beneficial to entrepreneurship. Although this can be true, we show that the differential intensity of social networks of Catholic and Protestant minorities in Europe are alike.

Under these conditions, the differential effect of Protestant culture versus Catholic culture on entrepreneurship can be identified by comparing the effects on the probability of being entrepreneur when part of a Protestant minority with that of being part of a Catholic minority.

In what follows we will first discuss each of the assumptions upon which our research design rests, then we will present the empirical analysis based on the identification strategy 
described above. We will start by discussing the inheritance of religious denominations from parents.

\section{Religion is inherited by parents}

Religion and religiosity are transmitted by parents to sons, generation after generation (Hoge et al., 1982; Clark and Worthington, 1987; Ozorak, 1989; Hayes and Pittelkow, 1993; Bañas and Noemann, 2006). A rather large number of people turn atheist, especially in the last decades when we have assisted to an acceleration of the process of secularization in Europe, but very few people convert to another confession or religion.

Looking at the data of the newly released ISSP Religion III survey collected in 2008, 96 percent of respondents with two Catholic parents have been raised Catholic. This figure is only slightly smaller for Protestants (94 percent). Of those raised Catholic, 83 percent continue to follow their denomination when adult, while 16 percent turn atheist and only about 1 percent convert to Protestantism. The parallel figures for Protestants are 79 percent, 20 percent and 1 percent respectively. When we exclude Eastern European countries, where atheism was promoted by the Communist regimes, we find that 80 percent of Catholics and 79 percent of Protestants maintain the religion they were raised in and 19 and 20 percent respectively convert to atheism. Overall, about 80 percent follow parents' confession with a slightly higher persistence among Catholics. These proportions change somewhat among minorities. Among Protestant minorities, 66 percent keep parents' religion, 26 percent turn atheists and 8 percent convert to Catholicism. Similar numbers are observed among Catholic minorities. Such higher erosion is partly explained by the fact that only about 50 percent of people belonging to a minority marry someone with the same religion, compared to more than $80 \%$ in the total population ${ }^{4}$.

Data show that conversion to another confessions is uncommon. Instead, as seen, many people become atheist, despite having being raised in a religious household. They are about 4.95 years younger [c.i. $4.23-5.48$ ], 11 percent [c.i. 9-13] more likely to be male, 13 percent

\footnotetext{
${ }^{4}$ Similar patterns have been found using both ISSP Religion 2 (1998) and ISSP Religion 1 (1991) data on subsamples of countries, except secularization being less pronounced.
} 
[c.i. 11-15] more likely to be employed and they have on average 1.30 additional years of education [c.i. 1.16-1.44] $]^{5}$. On the other hand, conversion from atheism to either Catholicism or Protestantism is limited: 83 percent of those raised atheist continue to declare themselves atheists, 5 percent convert to Catholicism and 12 to Protestantism.

\section{Minorities are stable over the long run}

The formation of Protestant and Catholic minorities in Europe is much related with the pattern of conversion to Lutheranism during the Sixteenth and Seventeenth Centuries in a population uniformly Catholic for at least eight centuries. At mid Seventeen Century, Central Europe, under the flag of the Holy Roman Empire, was a patchwork of confessions, with Catholic enclaves surrounded by Protestant territories and vice versa. This pattern was the outcome of a weak central power. The number of fiefs and free cities, some comparatively large and same so small to include only one village, which composed the Empire at the time of the Augsburg Peace (1555) was 225. In most cases, even the largest were not territorially compact but much fragmented because of the continuous marriages between prince families. All were pursuing larger autonomy from the Emperor. In this context, religion was not only a matter of spirituality but a weapon in the political arena between the emperor, the church and the nobles.

Although formally banned with the Edict of Worms, Lutheranism continued to diffuse and many princes converted. In 1531 the Schmalkaldic League was created among the protestant territories as a mutual defense against the emperor. Although the League was defeated and dispersed in 1547, Lutheranism was legitimated in the Peace of Augsburg (1555). The rule "cuius regio eius religio" (whose realm, his religion) was established, which granted the rulers the right to decide the official and unique religion of their territories. Their subjects could either subscribe the choice or leave the territory with their possessions. This rule applied with two

\footnotetext{
${ }^{5}$ t-test based across the sample of people coming from a household where both parents were religious, either Catholic or Protestant, who turn atheist and the sample of people with the same background who remains religious, controlling for country dummies.
} 
exceptions. In the ecclesiastical territories, the Prince-Bishops converted to Lutheranism had to abandon the power and be replaced by a Catholic. Their subjects could continue to practice their faith, either Catholic or Lutheran (Reservatum Ecclesiasticum). At the same time the Declaratio Ferdinandei exempted some of the cities from the requirement of religious uniformity, if the reformed religion had been practiced there since the mid 1520s, allowing for a few mixed cities and towns where Catholics and Lutherans lived together.

The result of these rules coupled with the Empire fragmentation was a rather dispersed geographical distribution of Protestantism and Catholicism in Central Europe ${ }^{6}$. In the Northern territories Protestantism was dominating with the notable exceptions of large ecclesiastical fiefs, such as the Bishoprics of Munster and Wurzburg and the Archbishoprics of Magdenburg and Tier besides the several free cities of Bremen, Hamburg and Lubeck. The South was predominantly Catholic, with the traditionally Catholic Bavaria and Austria, but with several free cities such as Augsburg, Ulm and Krepten largely or significantly protestant. The same Wurttemberg (the second larger southern fief) joined the Schmalkaldic League before being restored to Catholicism.

Essentially the same religious pattern emerged four centuries ago is present in Central Europe nowadays. This is apparent comparing Figure 1 and 2. In the former we have reported the map of the Holy Roman Empire after the Westphalia Treaty (1648), highlighting the Habsburg domains, Bavaria, and the Ecclesiastic possessions, that is the areas with a massive Catholic presence. In the latter we represent the same area nowadays with the proportion of Catholics in each region. The two matches to a large extent. For instance the regions bordering with the Netherlands, covered by the important Bishopric of Munster show a significant Catholic population still today, although the Netherlands and the remaining Northern Germany are traditionally Protestant.

\footnotetext{
${ }^{6}$ Religion wars continued in Europe for almost hundred years. The peace of Westphalia (1648) which ended the Thirty Years war confirmed the religious situation emerged one century before with the Peace of Augsburg. Furthermore, it made the imperial power more symbolic than real, wiping out its chances of achieving the goal of a unique religion in the Empire, thus guaranteeing the ultimate enrooting of Protestantism.
} 


\section{FIGURES 1 AND 2 AROUND HERE}

These patterns are confirmed by Spenkuch (2011) who recently collected historical information about the prevalent religion in 1555 and 1624 in each of the modern German counties. Past prevalent religion has been determined by taking into account the size of the fiefs included within the borders of the current counties (detailed information on population being unavailable). The religion of each fief is that of its ruler, which legally determined also the religion of the subjects due to the "cuius regio eius religio" principle. Comparing the geographical distribution of confessions in 1624 with today's distribution, it emerges that the two largely overlap. Moreover, by using German Socio-Economic Panel (SOEP) microdata, the author finds that the probability of an individual reporting to be protestant today (compared to Catholic or Atheist) is significantly higher in counties that were prevalently protestant in 1624.

We complement Spenkuch's analysis in two ways. First we compare the proportion of historically protestant counties ${ }^{7}$ in each of the modern German landers (our geographical unit of analysis for Germany) with the proportion of Protestant fellows today, taking into account only religious people to be consistent with the historical data. The correlation is as high as 0.87 when we focus only to the landers of the former Federal Republic of Germany and as high as 0.90 when we consider all German landers ${ }^{8}$.

\section{[TABLE 1 ABOUT HERE]}

Secondly, we do not consider landers, which are a relative recent administrative unit, but we look at German Catholic dioceses whose boundaries in many cases almost perfectly

${ }^{7}$ We rely on Spenkuch (2011) dataset and account mixed counties (i.e. without a prevalent religion) both to the set of Protestant and to the set of Catholic counties with a weight equal to $1 / 2$.

${ }^{8}$ However, in the East, fifty years of communist regime, less than 30 percent of the people report to be religious. 
reproduce those of the antic bishoprics, such as in the case of the dioceses of Mainz, Munster, Wurzburg. There are 27 Catholic dioceses in today's Germany compared to 16 Landers and more than 400 counties. Indeed, on the one hand dioceses are disaggregated enough to generate a good amount of variability and on the other hand, given their size, their religious composition will not be significantly altered by the physiological mobility of the residents at a more disaggregated geographical level. As a further advantage it is relatively simple to associate to each diocese the corresponding fiefs at the time of the Thirty Years War and gauge their relative importance. In Table 1 for each Catholic diocese we have reported the proportion of Catholics nowadays, the most important Catholic and Protestant territories in 1618 totally or partially included in the current diocese borders and an evaluation of the relative importance of the protestant territories compared to the catholic, based on their relative size. We find that the correlation between the proportion of Catholic residents nowadays and the historically relevance of Protestantism (measured over a five steps scale, where 1 is highest importance) is as high as 94 percent.

Outside Germany, persistence of religious distribution is even more apparent in Switzerland and the Netherlands. For instance, in Switzerland the modern cantons of Berne, Neuchatel, Vaud are today predominantly protestant as their territories were in the aftermath of the Reform. Furthermore, they enclose the canton of Fribourg which is largely Catholic today as it was five centuries ago with its episcopal see. The canton of Grisons is religiously mixed today following the tradition of "religious parity" of the Federation of the Three Leagues. In current Netherlands, the southern provinces of North Brabant (partly) and Limburg were included in the Spanish Netherlands and today maintain the traditional Catholic confession. In the eastern provinces of Gelderland and Overijssel there are Catholic minorities in the territories at the border with the German Archbishopric of Munster.

Although we do not detail religious distribution and its historical evolution for each European country, these results indicate that religious geographical distribution is very persistent over time. Actually the proportion of Catholics and Protestants over the total of the religious people tend to remain stable over time whatever the geographical or administrative unit we consider, meaning that both majorities and minorities tend to replicate themselves. This historical persistence support our claim that, to religious people, 
the condition of being part of a minority or of a majority is by and large exogenously determined.

\section{Minorities are more adherent to ethical norms}

Although minorities suffer from a certain erosion, it has been suggested in the literature that members of minority religions are the perfect believers, because they are more religious and more observant of the ethical norms compared to the followers of the same religion when they are majority. This may be true for at least two reasons. First because ministers of a minority religion work harder to defend its identity against the competition of other religions (market-share hypothesis, Stark, Finke, and Iannaccone 1995; Finke and Stark 1998; Stark 1997). Second, because religion is an important factor of people identity, beside language, history and culture, and it is considered by its followers a value to be preserved against the influence of the majority (Bisin and Verdier, 2000 and Bisin et al, 2004).

According to this view, the religious culture is better observed in minorities, while it is rather diluted and contaminated in majorities.

To illustrate this fundamental point of our identification strategy we will initially present a simple analytical model that describes both the choice of following parents' confession versus turning atheists and the degree of adhesion to religion. Next we will provide several pieces of supporting empirical evidence.

\section{Analytical model.}

Suppose that each individual inherits from parents a certain degree of adhesion to parents' confession $\alpha_{0} \in\left[0, \alpha_{\max }\right]$ and resides in a region where the proportion of residents sharing his same confession is $S \in(0,1]$.

The degree of adhesion physiologically reduces over time if not actively cultivated. Furthermore we suppose that the inherited $\alpha_{0}$ depreciates more when the size of the community of believers $S$ is small, such as it is the case among minorities, because of the 
incessant influence of the surrounding larger religious communities. Accordingly, let $\delta(S)$ be the depreciation factor and assume $\delta^{\prime}(S)>0$.

People can counter depreciation and even increase their degree of adhesion by investing time and resources in religion. Define $A=\alpha_{0} \delta(S)+\pi \alpha_{0} I$ the degree of adhesion after the investment $I$ has been made. Marginal returns of investment $\pi \alpha_{0}$ are higher for individuals with high inherited $\alpha_{0}$ because they have already been exposed to the particular confession's culture. Investment is costly and let its cost be $C=c I$.

Individuals value "identity" and tend to preserve it. Adhesion to parents' religion is part of individual identity. To maximize their utility, individuals decide whether to follow parents' religion or turn atheists, and the level of investment in religion. We neglect the possibility of turning to another confession as this is uncommon in practice.

Let people utility if they decide to keep parents religion be

$$
U^{R}=A^{\frac{1}{2}} g(S)^{\frac{1}{2}}-C=\left(\alpha_{0} \delta(S)+\pi \alpha_{0} I\right)^{\frac{1}{2}} g(S)^{\frac{1}{2}}-c I
$$

where $g(S)$ is a decreasing function of $S$ which aims at capturing the fact that preserving identity is more salient in small communities. An alternative interpretation of $g(S)$ is that the clergy is more effective in reinforcing people adhesion in small communities of believers. For the sake of simplicity, we normalize the utility from the option of turning atheists to

$$
U^{A}=\bar{U}
$$

i.e. a level independent of the size of the community.

Preliminary individuals determine which level of investment in adhesion is optimal and next they compare the (maximum) utility their derive from being religious or atheist.

The first order condition of (1) yields

$$
I^{*}=\frac{g(S) \pi \alpha_{0}}{4 c^{2}}-\frac{\delta(S)}{\pi}
$$

so that, ceteris paribus, optimal investment is higher if inherited adhesion is higher and if the size of the community is small, given that $g(S)$ is decreasing and $\delta(S)$ is increasing. The resulting amount of adhesion is then 


$$
A^{*}=g(S)\left[\frac{\pi \alpha_{0}}{2 c}\right]^{2}
$$

Indeed, the degree of adhesion will be higher in smaller communities.

By replacing (3) in (1) we get the optimized utility from being religious:

$$
U^{R *}=g(S) \frac{\pi \alpha_{0}}{4 c}+\frac{c}{\pi} \delta(S)
$$

Now, individuals decides to keep parents' religion when

$$
U^{R *}>U^{A}
$$

which amounts to

$$
\alpha_{0}>\frac{4 c}{\pi g(S)}\left[\bar{U}-\frac{c}{\pi} \delta(S)\right]
$$

We impose the following parameter restriction

$$
\bar{U}-\frac{c}{\pi} \delta>0 \text { all } S
$$

to avoid that (7) is trivially satisfied.

The first derivative of the left-hand-side of inequality (7) is

$$
-\frac{4 c}{\pi g}\left[\frac{g^{\prime}}{g} \bar{U}+\frac{c}{\pi} \delta\left(\frac{\delta^{\prime}}{\delta}-\frac{g^{\prime}}{g}\right)\right]
$$

which is negative if

$$
\frac{\delta^{\prime}}{\delta}>\frac{g^{\prime}}{g}\left(1-\frac{\bar{U} \pi}{c \delta}\right)
$$

As $\left(1-\frac{\bar{U} \pi}{c \delta}\right)<0$, given condition (8), inequality (10) is satisfied if the function $\delta(S)$ is sufficiently steep, i.e. if depreciation increase fast enough as long as the size of the religious community decreases.

In this case we can represent individual choice as in the following picture:

\section{[FIGURE 3 ABOUT HERE]}

The inherited degree of adhesion lays on the vertical axes and the size of individual's religious community on the horizontal axis. The downward sloping locus represent the 
frontier of inequality (7). For all pairs $\left(S, \alpha_{0}\right)$ located above the frontier, individuals prefer to keep and cultivate parents religion. Their degree of adhesion is given by expression (4). Conversely for the pairs $\left(S, \alpha_{0}\right)$ below the frontier, individuals turn to atheism.

The pattern that emerges is characterized by two features. First, individuals with high inherited adhesion $\alpha_{0}$ are over-represented among small communities while there is much more heterogeneity among large communities. Second, among small communities investment in religion as well as the degree of adhesion is higher, for any given $\alpha_{0}$.

\section{Empirical Evidence}

To test the strength of the correlation between adhesion and market share of a religion, we use again ISSP Religion III data. We look at nine possible outcomes, three related to the intensity of religiosity, five to articles of faith and one about confidence in churches and religious organizations. The first three are the average number of times an individual prays per week ${ }^{9}$, whether an individual prays regularly ${ }^{10}$, and a self-assessment of his/her religiosity, measured by a dummy which takes 1 when he reports to be "extremely, very or somewhat religious" and 0 when reports from "neither religious nor not religious" to "extremely not religious". ${ }^{11}$ Regarding articles of faith, we consider initially two of them which point to the specificities of Protestantism and Catholicism. People are asked whether they agree (on a scale from 1 to 5) with the statement "I have my own way of connecting with God without churches or religious services". Personal and unmediated relation with

\footnotetext{
9 Praying should depend mainly on individual religiosity and only marginally on the "supply" of churches and priests, opposed to attendance to religious services.

${ }^{10}$ Defined as at least once per month.

11 Although religiosity not necessary implies adhesion to given religious culture and norms, typically more religious people are also stricter observant. One reason behind this correlation is the action of the priests which transmit both religious norms and the need to actively profess own faith. Given this correlation, religiosity has been often preferred to religion denomination to measure the degree of attachment of individuals to religious cultural beliefs (McCleary and Barro, 2006).
} 
God is one tenet of the Protestant confession, which acknowledges a minor role to the clergy and the religious institution compared to the Catholic confession. Next, respondents express their agreement on the statement "There is little that people can do to change the course of their lives". This question is related to another point of differentiation between the two confessions, i.e. predestination. On the one hand Catholicism states that salvation can be obtained and deserved by means of the good works. On the other hand Protestantism indicates that salvation is a God's grace and that good works only signal individual fate but cannot alter it. We derive two dummies taking one when the individual strongly agrees or agrees and zero otherwise. The following three articles of faith are common to both confessions and regard beliefs in life after death, in heaven and in hell. We coded them as dummies which take 1 if individuals answer "yes, definitely" or "yes, probably" and zero if they answer "No, probably not" or "No, definitely not". Finally, the last outcome is confidence in churches and other religious organizations, which is coded 1 is respondents report complete or a great deal of confidence and zero from some to not at all confidence.

The estimated empirical equation is

$$
Y_{i r c}=\alpha_{0}+\alpha_{1} P_{i r c}+\alpha_{2} m_{i r c} P_{i r c}+\alpha_{3} m_{i r c} C_{i r c}+X_{i r c} \beta+\mu_{N 1}+\varepsilon_{i r c}
$$

over the restricted sample of those declaring to be Catholic or Protestant ${ }^{12}$. The alternative outcomes $Y_{i r c}$ of individual $i$ living in region $r$ (defined at NUTS 2 whenever possible ${ }^{13}$ ) of country $c$ are regressed over individual confession, captured by the dummy $P$ ( 1 is for

12 We exclude individuals belonging to the following religious denominations: Christian Orthodox, Jewish, Muslim, Eastern Religions, other denominations.

${ }^{13}$ In ISSP data regions are defined at a level of geographical disaggregation which ranges from an equivalent of NUTS1 to NUTS3 (sometimes imperfect) and in few cases it has no clear correspondence with the standard classification (e.g. for Denmark). We have estimated the model by defining regions as geographical entities aggregated at least at level NUTS2, the most common level in the data. Furthermore, to reduce measurement errors due to sampling, we have retained only regions with more than 30 observations. 
Protestantism), and two interactions, $m P$ and $m C$ which take on 1 when the individual's confession (resp. Protestant and Catholic) is minority in his region of residence. Next gender, age, years of education, employment condition, urban or rural residence, generally denoted by $X$, are included as controls, as well as regional (at NUTS 1) fixed effects $\mu_{N 1}$ which capture regional characteristics common to all residents irrespectively of their faith. Coefficients $\alpha_{2}$ and $\alpha_{3}$ identify the differential effect of minorities compared to the remaining population of the same faith. This is a model somewhat similar to that estimated in Gruber (2005).

We have tried alternative definitions of minority and remarkably results do not change qualitatively across definitions ${ }^{14}$. Indeed the geographical distribution of minorities and majorities in Europe follows a clear geographical pattern which is robust to alternative sensible definitions of what a minority and a majority are. For sake of brevity, we report only estimates based on the following definition:

Definition 1 (Minority): confession $d_{i r}$ of an individual $i$ residing in region $r$ is considered minority if a) its market-share in region $r$ is less than $25 \%$; and b) the market-share of $d_{i r}$ is the smallest in region $r^{15}$.

Thanks to the richness of ISSP data regarding religious family background, market shares are defined, in this section only, not on respondents' religion but on the religion of their parents. This allows to better identify the long term religious distribution in the regions, avoiding the fluctuations connected with the recent secularization ${ }^{16}$.

14 See the appendix B for further discussion.

15 This is the most stringent among the definitions we have tried. In ISSP data only about 3 percent of the sampled Protestants reside in regions where they are minority; the corresponding figure for Catholics is slightly more than 1 percent. These percentages would increase to about 8 and 4 percent respectively if we removed requirement b) from Definition 1

${ }^{16}$ In practice, there is no significant difference in our results when market shares are defined on the basis of the respondent's religious denomination. 


\section{TABLE 2 AROUND HERE}

Estimates are reported in Table 2 for each outcome. As expected, religious minorities tend to pray more and more regularly, are more religious than their "non-minority" counterparts $^{17}$. This results contrasts with Gruber (2005)'s, where a positive relation has been found in the US between attendance to religious services and the share of residents sharing the same confession, in spite of the similar specification of the model.

Turning to the articles of faith, minority Protestants tend to agree more with the principle of a direct and unmediated relationship with God, compared to other Protestant. Symmetrically, minority Catholics believe more than other Catholics that salvation can be achieved by means of good works and that individuals' fate is not predetermined. Turning to common articles of faith we find that the minorities of both confessions are more likely to believe to the life after death, heaven and hell. Finally both minorities tend to have more confidence in churches, and unsurprisingly more so among minority Catholics.

Although religious norms and article of faith are only a part of the broader collection of ethical, cultural and social norms that a religion is likely to convey as a religious culture, it is reasonable to think that adhesion to religious and other kind of norms are correlated, and that stronger adhesion to religious norm signal stronger adhesion to a broader religious culture.

\section{A possible confounder: social networks}

Unfortunately the condition of being minority brings about also stronger networks and social capital, which could favor entrepreneurship. Social networks tend to be stronger among minorities because cooperation is easier to achieve among smaller communities which share similar values and cultural traits (McPherson et al. 2001). Indeed we observe

\footnotetext{
${ }^{17}$ The estimate p-value associated to the parameter of "minority Catholic" in column (3) is 0.059 .
} 
that minority religions are typically over-represented among the entrepreneurs as suggested by the so called "middle-man theory" (Bonacich , 1973): either minorities act as mediators between other social groups, or minorities express a strong demand for mediation. Historically, the Jews have developed commercial and financial networks resting on the small communities scattered among European cities (Botticini and Eckstein, 2005). In this case it is not the Jewish religion alone which favored entrepreneurship, but also the peculiar conditions that such religion are likely to have favored, such as close connection and trust among its fellows (Dana, 2006). Moreover, Dana (2009) reviews several examples of financial, employment and information networks that emerge between people of the same religion. Ellison et al. (2009) and the references therein, suggest that small congregations provide their members with support and protection in case of shocks, much more than large communities.

Thus a stronger social connection could be the key to successful entrepreneurship. In Appendix A we explore whether this is the case in Europe with Catholic and Protestant minorities $^{18}$, by using data collected in the ISSP survey on Social Networks II produced in 2001 and estimating equation (11) on a battery of social network indicators. These are: the number of close friends on the workplace, in the neighborhood and in clubs, church and other associations; participation to voluntary associations; whether the respondent can potentially borrow large amounts from relatives and friends; whether the respondent has actually lent money to relatives and friends; whether he heard about his current work for relatives and friends; whether he helped someone outside of his/her house-hold with housework or shopping; whether he helped someone or to find a job; whether there are many people the respondent trusts completely; and whether he thinks that the others will take advantage of him if they had the opportunity.

We find absolutely no evidence of a systematic difference between minorities in terms of social connection. Actually, we have also found no difference between minorities and "nonminorities", a fact that confirms the absence of religious discrimination in modern Europe.

18 We focus on the set of European countries excluding those with Christian Orthodox majorities. 
These results are reassuring about the ability of our research design to identify the effects of religious culture on economic outcomes.

\section{The Empirical Model}

We aim at estimating the differential effect of Protestantism (compared to Catholicism) on the propensity to become an entrepreneur. Consider the diagram in Figure 4. The propensity to entrepreneurship is displayed on the vertical axis and the degree of adhesion to a religious culture lays on the horizontal axis. The degree of adhesion is a latent variable which we do not observe directly. Rather, we observe the market share of each confession which is correlated with the degree of adhesion, as we have discussed in section 3.3. Yet, the precise relation between adhesion and market share is unknown and likely to be non-linear. Rather than assuming a particular functional form for this relationship ${ }^{19}$ and risking a misspecification, we opt for a less direct approach which only looks at the "boundary" conditions of majorities and minorities and makes use of the fact that the average adhesion among majorities is significantly lower than the average adhesion among minorities.

In the diagram, when the degree of adhesion is zero, the propensity to self-employment is unaffected by the religious culture and fully depends on other factors, whatever the confession. In this case, the reported confession is merely a label which does not carry out any specific content and has no consequence on entrepreneurship. This is our key model specification hypothesis and we refer to it as the "common intercept hypothesis".

As far as the degree of adhesion increases, both confessions influence the propensity to selfemployment, possibly in a specific way ${ }^{20}$. The situation of complete adhesion is ideally the

19 The most natural (but likely not the best fitting) would be a linear mapping between degree of adhesion and the market share of each confession.

${ }^{20}$ In the diagram we have represented the map between adhesion and propensity to entrepreneurship as linear for the sake of simplicity. However, in principle, it could also be non-linear.. 
one we would like to observe in order to estimate the impact of a religious culture. Yet, as for the case of zero adhesion, complete adhesion is unobservable. We then approach the situations of zero and complete adhesion by looking respectively at the believers who belong to majority and minority confessions.

Minorities are defined as in Definition 1. Majorities are defined symmetrically as follows:

Definition 2 (Majority): confession $d_{i r}$ of an individual $i$ residing in region $r$ is considered majority if a) its market-share in region $r$ is larger than $60 \%$; and b) the market-share of $d_{i r}$ is the largest in region $r$.

Being relatively close to the intercept, we expect that the differential effect of Protestantism versus Catholicism between majorities will be small. Conversely, if any differential effect existed, it should be fully apparent between minorities as their members closely follow the norms and the values of their confession ${ }^{21}$.

\section{FIGURE 3 AROUND HERE}

We estimate a modified version of equation (11) maintaining the focus only on religious individuals $^{22}$. Differently from equation (11) the model explicitly accounts for the differential effects of both minorities and majorities. Formally, the equation we estimate is

$$
\begin{aligned}
Y_{i r c}=\alpha_{0}+\alpha_{1} P_{i r c}+\alpha_{2} M_{i r c}+\alpha_{3} m_{i r c}+\alpha_{4} M_{i r c} P_{i r c}+ & \alpha_{5} m_{i r c} P_{i r c}+ \\
& +X_{i r c} \beta_{1}+W_{r c} \beta_{2}+\mu_{c}+\varepsilon_{i r c}
\end{aligned}
$$

${ }^{21}$ Note that, given the hypothesis of common intercept, the latter difference (approximately) captures the full differential effect of Protestantism compared to Catholicism that we would observe in the case of complete adhesion.

22 Atheists have been left aside because they possibly differ from religious individuals in some key respects, such as risk aversion, as we will discuss in Section 7.5 and Appendix C below. 
where $Y_{i r}$ indicates whether individual $i$ living in region $r$ of country $c$ is self-employed, $P_{i r}$ is a dummy which takes one for individuals declaring themselves to be protestant, $M_{\text {irc }}$ is a dummy which takes one whether individual $i$ is part of a religious majority and $m_{\text {irc }}$ is another dummy which indicates whether individual $i$ is part of a religious minority. $M_{i r r} P_{i r c}$ and $m_{i r r} P_{i r c}$ are interactions between the majority/minority dummies and the protestant dummy, $X_{i r c}$ are individual level controls, $W_{r c}$ are regional level controls, $\mu_{c}$ are country fixed effects and $\varepsilon_{i r}$ is an IID error term ${ }^{23}$.

From model (12) we can both derive the differential impact of Protestantism and test the common intercept hypothesis. The differential impact of the Protestant culture $D$ is defined as the simple difference

$$
D=\left[E\left(Y_{i r c} \mid P_{i r c}=1, m_{i r c}=1, X_{i r c}, W_{r c}, \mu_{c}\right)-E\left(Y_{i r c} \mid P_{i r c}=0, m_{i r c}=1, X_{i r c}, W_{r c}, \mu_{c}\right)\right]=\alpha_{1}+\alpha_{5}
$$

which turns to be equal to $\alpha_{1}+\alpha_{5}$ in terms of the estimated parameters.

By taking differences, the differential effect of Protestantism is purified of common confounders such as a possible higher intensity of social connections among minorities.

The specification test of common intercept is provided by another simple difference now taken between majorities, which is close to the situation of zero adhesion.

$$
\begin{aligned}
& \operatorname{TEST}=\left[E\left(Y_{i r c} \mid P_{i r c}=1, M_{i r c}=1, X_{i r c}, W_{r c}, \mu_{c}\right)-E\left(Y_{i r c} \mid P_{i r c}=0, M_{i r c}=1, X_{i r c}, W_{r c}, \mu_{c}\right)\right]= \\
& =\alpha_{1}+\alpha_{4}
\end{aligned}
$$

The specification test passes if condition (a) $\alpha_{1}+\alpha_{4}<\alpha_{1}+\alpha_{5}$ (i.e. $\alpha_{4}<\alpha_{5}$ ) is satisfied, and, if the stronger condition (b) $\alpha_{1}+\alpha_{4}=0$ cannot be rejected. Without explicitly requiring condition (b), we could not invoke a continuity-based argument to claim that the hypothesis

23 A variant of model (12) includes regional fixed effects defined at NUTS 1, a broader level of geographical aggregation than the one used to define minorities and majorities, see below. 
of common intercept holds. If (b) failed, we could be in a case where Protestants differ from Catholics even at zero adhesion, a puzzling situation that would suggests either that the model is ill-specified or that we omit to control for important confounders.

\section{Data}

Our sample consists of European Social Survey (ESS) data collected every two years from 2002 to 2008 in a number of Western and Eastern European countries. We select all countries where Orthodox religion is not majority and exclude all non-Christian religious minorities, ending up with 22 countries, 148,234 individuals in the sample, of which 78,889 are active in the labour market. The countries selected in our sample include the major Western-European and a number of Eastern-European whose religious tradition is not Orthodox. They are Austria, Belgium, Italy, Luxembourg, Czech-Republic, Netherlands, Denmark, Norway, Estonia, Poland, Finland, Portugal, France, Slovakia, Germany, Slovenia, Spain, Hungary, Sweden, Switzerland, Ireland, United Kingdom. Table B1 in the Appendix shows the participation of each country to each wave of the ESS.

European regions are defined according to the population dimension. The ESS data provide different levels of regional aggregation, from NUTS 1 to NUTS 3, the latter only available for some selected countries. We define minorities and majorities at the most disaggregate level available for each country, but we check whether our results are robust to changes in the adopted criteria ${ }^{24}$.

\section{FIGURES 5, 6, 7 AROUND HERE}

Table 3 displays the proportion of the three religious denominations in each country included in the sample, while figures 5 to 7 display the proportion of, respectively, Catholics, Protestants and atheists across European regions (NUTS 2). Atheists represent $43 \%$ of

${ }^{24}$ See appendix B for a broader discussion on this point. 
individuals in our sample while Catholics and Protestants are, respectively, 39\% and 18\% of the total. Figure 8 and 9 report the proportion of Protestant and Catholic minorities across European regions.

\section{FIGURES 8, 9 AROUND HERE}

\section{TABLE 4 AROUND HERE}

The first column in Table 4 and Figure 10 show instead the proportion of the surveyed individuals who are self-employed, while the second and third columns of Table 4 and Figure 11 provide more detailed information on the characteristics of the surveyed selfemployed in terms of dependent employees, if any. Czech Republic, Estonia, France, Hungary, Slovenia and Slovakia are the countries with the smallest proportion of selfemployed. Predominantly Catholic countries, such as Italy, Poland, Spain and Portugal, are instead the countries with the largest proportion of self-employed individuals over total employment. Of course, such simple correlation is not very informative since it is driven by all sort of country-specific unobservable factors that affect both religion and entrepreneurship. Looking at various definition of self-employment, i.e. self-employed with, respectively, at least one and ten dependent employees, we see how the extent of the entrepreneurship phenomenon is variously declined in terms of business dimension. Indeed, the proportion of entrepreneurs with many employees is quite diverse across countries.

\section{FIGURES 10, 11 AROUND HERE}

We estimate model (12) adopting a linear probability model specification, clustering individual standard errors across European regions. Individual controls include age, gender, if foreigner, years of schooling, marital status and a wealth variable indicating whether the main source of income is financial. In addition we can exploit one of the specificities of ESS data, i.e. the availability of information on entrepreneurial family background, i.e. whether the father was self-employed. Family background is of particular relevance since we are able to distinguish between individuals who inherited a business (or a propensity to be selfemployed) from those who were not expose to such advantage. In addition, we include a 
full set of area (country or regional) and time fixed effects, in order to control for country (or region) unobservable characteristics, and common cyclical factors. In some specifications we include time varying regional controls. These include regional GDP growth, population density, unemployment rate, number of doctors per capita as a proxy for social development, educational attainment at regional level and the extension of motorways as a proxy for infrastructures (source: Eurostat). Summary statistics are reported in Table B2 in the appendix.

\section{Results}

Column 1 in Table 5A displays our estimated baseline model, resulting from specification (12). According to our estimates, adhesion to Protestantism induces a higher propensity of being self-employed with respect to Catholicism. More specifically, our baseline model points to a statistically significant increase in the propensity of being self-employed equal to 3.3 percentage points if minority Protestant compared to a minority Catholic. This is the differential effect $D$ we discussed in Section 4, i.e. the estimated difference in the propensity of being an entrepreneur when truly adhering to Protestantism versus Catholicism, which is displayed in the lower part of Table 5A and is indicated as "MinP-MinC". The effect is sizable considering that the average likelihood of being an entrepreneur in Europe is about 10 percent.

\section{TABLE 5A AROUND HERE}

As indicated by the model estimated in column 2, this result is robust to the exclusion of potential endogenous variables such as education, marital status and whether the main source of wealth is financial that could in principle confound the interpretation of our results within our research design's setting. The estimated effect is indeed almost identical when dropping potentially endogenous controls. Similarly, we find identical results when we control for the characteristics of the regions used for calculating religious minority patterns 
across Europe. The model in column 3 includes the time varying regional macroeconomic controls discussed above with almost identical findings.

For each of these models the identification assumptions of our empirical strategy have been tested. The parameter associated to $M P$ (majority protestant) is always smaller than that associated to $m P$ (minority protestant) as expected. Furthermore we checked whether there exists a significant effect of being a Protestant in Protestant majority regions versus being a Catholic in Catholic majority regions. The quantity "MajP-MajC" in the lower part of Panel $\mathrm{A}$ in Table 5 is the corresponding differential effect TEST introduced in Section 4. We always fail to reject that MajP-MajC is equal to zero in any of the specifications and therefore our common intercept hypothesis is never rejected by the data. All combined results indicate that the effect of the cultural determinants embodied by religious denominations have a significant impact on individual choices when the adhesion to religion is strong, as it is among minorities. Instead the effect is absent when the adhesion is less strong, as it is among majorities.

Our results are tested in Table 5 Panel B against a number of robustness checks ${ }^{25}$. In column 1 the differential effect of Protestantism is robust to the inclusion of NUTS1 regional fixed effects instead of country fixed effects, thereby controlling for unobservable factors at a less aggregated geographical level. Here the effect of interest is almost identical to what found in the baseline model. Our results also holds when we only consider regions where respondents of both religious denomination are represented in the sample, as in column 2. In this case the number of observations drop by almost 2600 units with no appreciable effect on our estimated effect. In column 3 minorities are calculated at a NUTS 1 regional level in order to get an homogeneous regional disaggregation level across countries. This means that whenever ESS provides information on respondents' region of residence at NUTS 2 and 3 level, we aggregate at NUTS 1, and calculate whether and which religious denomination is minority. Similarly, in column 4 minorities are calculated at NUTS 2 level. In these cases the estimated effect is only slightly larger than previous columns (in both cases 3.6 percentage points instead of 3.3 percentage points).

\footnotetext{
25 See also the additional discussion and further robustness checks of section 7 below.
} 


\section{TABLE 5B AROUND HERE}

Finally, column 5 displays our model estimated on individuals who are employed instead of just active. Around 5\% of individuals in our baseline sample are unemployed. Since we know their occupation and employment status (if any) during their last occupation, and since we are interested in the causal effect of cultural determinants on labour market choices we do not have any reason not to include respondents who are unemployed at the moment of their interview. However, in principle, these individuals may be characterized by peculiarities that do not make them necessarily homogeneous to the rest of our sample. Nevertheless, when we exclude unemployed respondents in column 3, our point estimates does not change, confirming our intuition.

As regards the typical effects of controls, the likelihood to be self-employed increases by around 13 percentage points if father was self-employed, 9 percentage points if male and 10 percentage points if main source of income is financial. Being foreigner is not significantly different than being national, and the effect of education is mixed.

We have also estimated model (12) by using ISSP Religion I and II data, which cover the decade before the one we have analyzed so far. The first obvious interest in this exercise is that of testing the robustness of our results in a different time period. The second motivation is the presence in ISSP of very detailed information on parents' religion. Religious family background is a rather accurate measure of the cultural environment of the family where the respondent has grown up. Nevertheless, ISSP has also two drawbacks: it does not include information on parents' entrepreneurship, and minority definitions can become too restrictive, because of the smaller sample size compared to ESS. We have then estimated model (12) replacing entrepreneurial with religious family background. Overall results remain qualitatively similar, although not always precisely estimated. There is a tendency to have larger effects of protestant ethics compared to what we obtained by using ESS, most likely due to the omission of the highly relevant entrepreneurial family 
background. Using ISSP, we have also considered the confession the respondent was raised in rather than his current religious denomination and we have defined regional market shares accordingly. In so doing we should capture the cultural background each individual has been exposed to during childhood and which is not observed by looking at current denomination. Results remain stable, as one could predict given our earlier results suggesting that transitions between confessions are small. This also suggests that current religious denomination is an acceptable indicator of religious cultural background.

\section{Discussion and Further Robustness Checks}

\subsection{Geographical Patterns of Protestantism and Catholicism in Europe}

Our estimates indicate that the likelihood of being an entrepreneur is about 3 percentage point larger among individuals endowed with a Protestant religious cultural background with respect to individuals characterized by a Catholic religious background, ceteris paribus. This is a sizeable difference as the average likelihood of being an entrepreneur in Europe is about 10 percent. The finding is remarkably stable and passes a series of robustness checks.

However, a number of issues need to be further investigated in order to correctly interpret our findings. The first issue has to do with the peculiar distribution of minorities across European regions. In principle we cannot exclude that, despite originating from exogenous historical factors, the concentration of minorities in peculiar geographical areas for reasons not directly related to religion may in some way affect our findings. Looking at Table 3, Europe is characterized by two macro-regions with a strong concentration of confessions, i.e. Scandinavia and the Mediterranean area. Indeed, Scandinavian religious individuals are vastly Protestant and religious individuals in Mediterranean countries are vastly Catholic. The geographical distribution of minorities in Figures 8 and 9 is then partly the product of this peculiar geographical pattern of European Protestantism and Catholicism. Despite the distribution of minorities being not so clear-cut across European regions, these two clusters in Protestantism and Catholicism may in principle be a reason for concern. It could be possible that by comparing the behavior of individuals belonging to minorities across regions 
we may indeed be confounded by the structural characteristics of these specific European macro-regions in terms of institutions and general economic environment, more or less conductive to entrepreneurship. In addition, if some macro-areas were traditionally more tolerant than other versus religious minorities, the ability of such minorities in establishing entrepreneurship patterns could be strengthened, but this would have nothing to do with the ethical content of the minority religion. This particular channel may be at play when comparing Scandinavian and Mediterranean countries, with the former often traditionally considered more tolerant than the latter.

If this was the case, country or regional fixed effects could only capture part of the unobservable confounding factors, namely those affecting the constant parameter rather than the slope. It is therefore crucial to rule out that our estimation results do not depend on the inclusion of specific countries or larger geographical areas that are so intrinsically characterized by one of the two confessions.

For example, it could be that minority Protestant enjoy personal and environmental conditions which are systematically more conducive to entrepreneurship than minority Catholics. If this is the case then our identification strategy would fail. However an inspection of the distribution of Protestant and Catholic minorities in Europe, shows that Protestant minorities live in Central and Southern Europe and Catholic minorities in Northern Europe. This pattern excludes that minority Protestants are systematically advantaged in terms of education, economic growth and economic institutions that are more favorable to entrepreneurship, actually it is quite the opposite as education attainment, school quality, economic growth, and rule of low are typically higher in Northern Europe.

\section{TABLE 6A AROUND HERE}

We can investigate this issue further by checking how our estimation results depend on the inclusions of specific countries. We therefore estimate our baseline model by restricting our sample of countries in a number of different ways. Panel A of Table 6 displays the results 
when excluding, respectively, Scandinavian countries (i.e. Norway, Sweden, Denmark and Finland, in column 1), Mediterranean countries (i.e. Italy, Spain, Poland, Portugal and Ireland, in column 2) and both (in column 3). The model in column 3 is therefore estimated only on data from countries where both Christian confessions co-exist and are characterized by a significant share of the religious individuals. Our main finding is robust to such a dramatic reduction in sample size, despite our sample being reduced by around 20, 30 and 50 percent, respectively (i.e. reaching a total of 28497, 24586 and 17294 observations instead of 35789). The estimated coefficients are close to our baseline estimate, and vary from a 3.3\% effect of Protestantism in column 1 to a $2.1 \%$ effect in column 3. The specification test is always respected, with no significant effect when comparing majorities.

Pursuing further this direction, in panel B of Table 6 we check whether our findings depend on the inclusion of specific countries in our sample, by dropping one country at a time. These estimates show how our main result is not driven by any of the countries in the sample. The estimated effect is always positive and significant, varying from a minimum of 2.9 percentage points to a maximum of 4.1 percentage points. This is an indication on how the systematic difference in individual attitude towards entrepreneurship across minority confessions does not appear to be the result of country specific patterns, but rather of a general tendency across European regions.

\subsection{Migration and Religion}

Another concern we need to take care of is the potential impact of recent migration waves on the geographical distribution of religious beliefs across Europe. We discuss above how the actual geographical pattern of Christian minorities across European regions is stable over the long run and closely resembles that which emerged from the peculiar events following Reformation. This finding by definition excludes that cumulative historical migration patterns may have played a significant role in changing the geographical map of the incidence of confessions across Europe. However, in principle it may be the case that modern migration patterns could be endogenously driven by religious factors as well as by 
the individual propensity to start or export a business abroad. In turn, this could possibly alter the estimated relationship between religion and entrepreneurship.

We check for the effect of migration in column 4 of Table 6 - Panel A by excluding all individuals who are first or second generation migrants, i.e. those who were born abroad or whose father was born abroad. We then both recalculate our minority indicators and reestimate the model considering national individuals only. The differential effect of Protestantism is still found positive ad significant and close to what found in our baseline estimation, amounting to around 2.6\%. Again, no significant effect is found when comparing majority individuals. In addition, when comparing the migrants' religion with the predominant religion of the host country we do not find any clear correlation. This is a further indication that our findings are not confounded by migration-related factors.

\subsection{Entrepreneurship as a Way Out of Discrimination}

Generally, entrepreneurship is more frequent among minorities because it represents a way out in case of discrimination. A possible objection to the validity of our results could be then expressed as follows.

It is commonly maintained that the Catholic Church is quite intransigent in condemning norms, behaviors and conducts contrary to its principles whereas the less hierarchical and dispersed Protestant churches look much more open and inclusive. Consequently, also Catholic people could be more intolerant than Protestants towards other faiths or beliefs. If this was true, then Protestant minorities, surrounded by catholic majorities, could be overrepresented among entrepreneurs, being entrepreneurship more than an option if one is discriminated, and, symmetrically, minority Catholics who live beside open-minded and tolerant Protestant majorities could freely offer themselves on the labor market and find more opportunities as dependent workers. As a result there should be comparatively more entrepreneurs among Protestant than among Catholic minorities, but this would have nothing to do with ethics or religion culture. 
In fact, the supposed higher tolerance of Protestant churches and Protestant people is not empirically grounded. According to Kaplan (2007), extreme intolerance was equally common across confessions and countries and lasted for at least 150 years after the end of the religious wars. Often Protestants were deeply intolerant, not only of Catholics but also of each other (such as the burning of Servetus, a Spanish Protestant, in Calvin's Geneva witnesses). In Britain and Ireland the civil war and the spread of Puritanism, the catholic intolerance of James II and the anti-Catholic Gordon riots are examples of intolerance from both sides.

Turning to present days and looking at ISSP Religion III data, we find that 82 percent of Catholics and 75 percent of protestant agree with the principle that all religions deserve respect, and about 80 percent of both confessions' fellows would accept that a close relative marries a person from a different religion. In the ESS data we have more specific information about discrimination, as respondents declare whether they are part of a discriminated group and whether discrimination is due to religious reasons. They also declare how much important is, in their view, understanding other people. We use this information as alternative outcomes in model (12) to test whether minorities and/or majorities differ across confessions ${ }^{26}$. To avoid any possible confounder related to the status of immigrant, we remove first and second generation immigrants from the sample. Results are displayed in Table 6 panel C.

Overall, we find that Catholic and Protestant minorities are not discriminated to a different extent, although both report some discrimination ${ }^{27}$. Point estimates indicate that minority Catholics are more likely to belong to a discriminated group. When it comes to discrimination due to religious motivations, the opposite occurs. However differences are never significant.

\footnotetext{
${ }^{26}$ As regards the importance to understand others, we define a dummy variable which takes 1 if the respondent declare very important or important.

27 The same proportion of minority Protestant and Catholics (1.7 percent) report to be discriminated on religious grounds. Among the remaining population, the proportion is again equal between confessions but lower $(0.7$ percent).
} 
Finally, neither majorities nor minorities differ according to the importance they attach to understanding others.

\subsection{Sectoral Composition and Entrepreneurship}

In panel D of Table 6 we examine whether sectoral composition at regional level may affect our estimates and how. In column 1 we control for sectoral composition at regional level using the EU KLEMS sectoral classification (O’Mahony and Timmer, 2009). Controlling for sectoral composition is motivated by possible different entrepreneurship patterns across industries. When accounting for the 15 major EU KLEMS industries we estimate a positive and significant differential effect of Protestantism, only marginally smaller than what previously found, i.e. around 2.5 percent. Our findings are robust even when we control for industry at the individual level (not included in the table).

In column 2 we focus on agriculture. Indeed, the agricultural sector is traditionally characterized by a high concentration of self-employed with respect to the rest of the economy, and agricultural communities are traditionally more religious than urban communities. We then exclude from our sample all individuals working in agriculture, which amounts to dropping around $4.5 \%$ of our observations. Our point estimate is still strongly statistically significant and close to our previous estimate at 2.7 percentage points.

Column 3 concentrates on our definition of entrepreneurs by excluding those self-employed individuals who are unpaid family workers, i.e. those who experience a peculiar form of compensation that may take other form that actual wages, such as, for example, increase in business value. In our sample only around 1\% of respondents (around four hundred) are subject to such form of self-employment, and the effect of this exclusion on our estimated effect is marginal (from 3.3 to 3.2 percentage points).

Our specification test is respected in all three columns, i.e. no significant differential effect is found when comparing individuals belonging to religious majorities. 


\subsection{Risk Aversion as an Explanatory Factor}

Finally, one aspect worth investigating further is the role of risk aversion that has been indicated as one important ingredient of entrepreneurship (see Kihlstrom and Laffont (1979); Ekelund et al. (2005) among many others).

In principle, being Catholic, Protestant or atheist might be correlated with several attributes of individual preferences. This is because both religion and some character traits are learnt in the family. For instance the growing literature of endogenous preferences suggests that time preferences (Doepke and Zilibotti, 2005) or trust (Guiso, Sapienza, Zingales, 2008) are partly decided and shaped by parents. Similarly, it is reasonable to suppose that risk aversion is learned in the family. We may distinguish two cases here. On the one hand, different patterns in risk aversion between Protestants and Catholics may be the product of the difference in cultural traits embodied by the two confessions. In this sense, the effect of risk aversion on entrepreneurship can be ascribed to the broader effect of religion and more generally risk aversion could be one of the channels through which culture may affect economic choices and outcomes.

On the other hand, risk aversion may be a causa prima that could motivate both an entrepreneurial attitude and the choice of a particular religion. If this was the case then by looking at the relationship between confessions and entrepreneurship we could find a spurious correlation.

In order to investigate this issue further, we have focused on Germany and we have used SOEP 2004 data to assess whether there are any differences between Catholics and Protestants in terms of risk aversion in that country. The overall message of the analysis, discussed in detail in Appendix $\mathrm{C}$, is that there are no systematic differences in terms of risk aversion between Catholic and Protestants. This is reassuring as any difference in the level of entrepreneurship between the two confessions cannot be ascribed to risk aversion. Instead we find less conclusive indications regarding the difference between religious people in general and atheists. There is some evidence that religious people could be more risk-averse than atheists. For this reason, in order to avoid the risk of bringing in unobservable 
confounders difficult to account for, in our analysis we prefer to always disregard the atheists and focus on the smaller but more homogenous sample of religious people.

Summarizing the results of our analysis, we identify an effect of cultural factors, represented by a religion the individual genuinely adhere to, on the choice of being an entrepreneur. This effect cannot be the result of a correlation between religious denomination and socioeconomic characteristics, such as education, economic development, sectoral composition or institutions at regional or country level. Actually, we can exclude any systematic differences between individuals who generically define themselves Protestants and Catholics since no difference remains between Protestant and Catholic majorities after controlling for a long battery of individual and regional covariates, in any of our specifications. Only when internalization of ethical norms and values is high, as it is the case among minorities, a significant difference in the impact of the two religious cultures emerges. This means that a historical, long lasting, religious tradition does not influence entrepreneurship per se. It is rather a genuine individual attachment to a specific religious culture, inherited through the family, that autonomously matters, in addition to all other elements we have highlighted in our analysis, including entrepreneurial family background.

Why Protestantism is more favorable to entrepreneurship than Catholicism? We can only speculate at this stage and further research is needed on this point. The emphasis of Protestantism on the individual, unmediated, relation with God seems to be an element correlated to the emergence of a strong sense of self and of self-esteem, two important ingredients to an entrepreneur. Moreover, Protestantism can produce a favorable social influence, i.e. the moral approbation towards success and wealth accumulation, which could be a further incentive to take the risky way of entrepreneurship. As social approbation develops only if the surrounding community shares the same Protestant ethics, this interpretation fits well with the finding that Protestantism is more conducive of entrepreneurship within minorities, where on average people are stricter observant. 


\section{Conclusions}

In this paper we suggest a methodology for identifying the implications of alternative cultural and social norms embodied by religious denomination on labour market outcomes in European regions. We test whether cultural norms represented by religious beliefs may affect individual labour market choices. More specifically, we investigate the differential impact of Protestantism versus Catholicism on the decision of becoming an entrepreneur by means of a quasi-experimental approach based on the minority status of religious denominations across European regions.

Differently from other contributions, such as Guiso, Sapienza and Zingales (2006), in this paper we concentrate on causality more than on the specific channel by which religious social norms may affect economic outcomes.

In our research design we exploit the exogenous historical determination of the distribution of religious denominations across European regions, the stronger degree of attachment to religious background of religious minorities, and the homogeneous general economic and cultural environment European Protestant and Catholic minorities are subject to, in order to elicit the role played by religious cultural background on labour market choices. Our findings suggest that cultural background has a significant effect on individual propensity to become an entrepreneur in Europe. Protestantism is found to increase the chances to be an entrepreneur by around 3 percentage points with respect to Catholicism. This result is robust across alternative specifications, to a number of robustness checks and does not depend on the inclusion of specific countries in the sample.

Our findings are not necessarily at odds with those of Becker and Woessman (2009) since the focus of our analysis is quite different from their investigation. In addition to the time framework being crucially different, we analyse the implications of religious denomination on the choice of becoming an entrepreneur among individuals who display a certain adherence to their creed (i.e. minorities), while Becker and Woessman focus on the implications of aggregate prevalence of Protestantism on economic growth at regional level just after Reformation. However, our results do suggest that moral considerations, ethics and 
culture substantially enter in labour market choices, therefore providing further evidence on the need to take cultural elements into consideration when analysing economic behaviour. 


\section{References}

Audretsch, D.B., Bönte, W. and Tamvada, JP. (2007) "Religion and entrepreneurship", CEPR discussion paper n.6378

Becker, S. and Woessmann L. (2009) Was Weber Wrong? A Human Capital Theory of Protestant Economic History, The Quarterly Journal of Economics, 124(2), 531-596.

Bénabou, R and J. Tirole (2006) "Belief in a Just World and Redistributive Politics", The Quarterly Journal of Economics, 121(2): 699-746.

Alberto Bisin \& Giorgio Topa \& Thierry Verdier (2004) "Religious Intermarriage and Socialization in the United States," Journal of Political Economy, University of Chicago Press, vol. 112(3), pages 615-664, June.

Bisin, A., and T. Verdier (2000) "Beyond The Melting Pot: Cultural Transmission, Marriage, And The Evolution Of Ethnic And Religious Traits", Quarterly Journal of Economics, 115:955988.

Blanchflower D. and Oswald A. (1998) What makes an entrepreneur? evidence on inheritances and capital constraints, Journal of Labor Economics, 16(1):26-60, January.

Blanchflower D.(2000), Self-employment in OECD countries, Labour Economics, 7(5):471505 , September.

Bonacich, E. (1973). “A Theory of Middleman Minorities”. American Sociological Review, Vol. 38, No. 5 (Oct., 1973), pp. 583-594

Botticini, M. and Eckstein, Z. (2005). Jewish Occupational Selection: Education, Restrictions, or Minorities?. The Journal of Economic History, 65 , pp 922-948

Brañas, P. and S. Neuman (2006), 'Intergenerational transmission of 'religious capital': Evidence from Spain" Papers on Economics of Religion - PER 06/02 
Carswell, P. and Rolland, D. (2004) "The role of religion in entrepreneurship participation and perception" International Journal of Entrepreneurship and Small Business, Volume 1, Numbers 3-4, pp. 280-286(7)

Clark, C. A. and Worthington, A. (1987), "Family Variables Affecting the Transmission of Religious Values from Parents to Adolescents: A Review," Family Perspective 21: 1-21.

Clark, K. and Drinkwater, S. (2000) "Pushed out or pulled in? Self-employment among ethnic minorities in England and Wales" Labour Economics 7: 603-628

Dana, L.P. (2006) "A historical study of the traditional livestock merchants of Alsace” Food Journal Vol. 108 No. 7 pp. 586-598

Dana, LP. (2009) "Religion as an explanatory variable for entrepreneurship", Entrepreneurship and Innovation vol 10, No 2, pp 87-99

Doepke, M. and F Zilibotti (2005) "Social class and the spirit of capitalism", Journal of the European Economic Association, 3(2-3): 516-524

Dohmen, T., A. Falk, D. Huffman, U. Sunde, J. Schupp, and G. Wagner (2005): “Individual Risk Attitudes: New Evidence from a Large, Representative,Experimentally-Validated Survey," Discussion Paper No. 511, DIW Berlin

Ekelund, J., E. Johannson, M. Järvelin, and D. Lichtermann (2005), "Self-employment and Risk Aversion - Evidence from Psychological Test Data," Labour Economics, 12, 649:659

Ellison, C.G., Krause, N.M., Shepherd B.C. and M.A. Chaves (2009) "Size, Conflict, and Opportunities for Interaction: Congregational Effects on Members' Anticipated Support and Negative Interaction", Journal for the Scientific Study of Religion, 48(1):1-15

Falck O. and L. Woessmann (2010) “School Competition and Students' Entrepreneurial Intentions: International Evidence Using Historical Catholic Roots of Private Schooling” CESIFO WORKING PAPER NO. 3086

Giavazzi, F., Schiantarelli F. and Serafinelli, M. (2009), Culture, Policies and Labor Market Outcomes, IZA D.P. 4558. 
Gruber, J. and D.M. Hungerman (2008) "The Church versus the Mall: What Happens When Religion Faces Increased Secular Competition?”, The Quarterly Journal of Economics, 123(2): $831-862$

Gruber, J.H. (2005) "Religious Market Structure, Religious Participation, and Outcomes: Is Religion Good for You?” Advances in Economic Analysis \& Policy BEpress, 5(1) Art. 5

Guiso, L., P. Sapienza, and L. Zingales (2006), "Does Culture Affect Economic Outcomes?," Journal of Economic Perspectives, 2, Spring, 23-48.

Guiso, L., Sapienza, P., and L. Zingales (2008a). “Alfred Marshall Lecture Social Capital As Good Culture", Journal of the European Economic Association, 6(2-3):295-320

Guiso, L., Sapienza, P., and Zingales, L. (2003), "People’s opium? Religion and economic attitudes", Journal of Monetary Economics, Vol 50, No 1, January, pp 225-282.

Guiso, L., Sapienza, P., and Zingales, L. (2009) "Cultural Biases in Economic Exchange", Quarterly Journal of Economics, 2009, forthcoming.

Hayes, B. C., and Pittelkow, Y. (1993), "Religious Belief, Transmission, and the Family: An Australian Study," Journal of Marriage and the Family 55: 755-766.

Hoge, D. R., Petrillo, G. H. and Smith, E. I. (1982), “Transmission of Religious and Social Values from Parents to Teenage Children," Journal of Marriage and the Family 44: 569-580.

Iannaccone, L. R. (1998). "Introduction to the Economics of Religion," Journal of Economic Literature, 36(3), pp. 1465-1495.

Kaplan, Benjamin J. (2007) Divided by Faith: Religious Conflict and the Practice of Toleration in Early Modern Europe. Cambridge, Mass. and London: Harvard University Press.

Kihlstrom, R., and J. Laffont (1979): “A General Equilibrium Theory of Firm Formation Based on Risk Aversion," Journal of Political Economy, 87, 719:748.

Lazear, E. P., (2002) “Entrepreneurship,” NBER Working Paper No. 9109. 
Marx, K. 1859. A Contribution to the Critique of Political Economy. New York: International Publishers.

McCleary, R. M. and R. Barro (2006), "Religion and Economy", the Journal of Economic Perspectives, Vol. 20. No 2, Spring, pp. 49-72.

McPherson, M., Smith-Lovin, L. and J.M. Cook (2001) "Birds Of A Feather: Homophily in Social Networks" Annual Review of Sociology 27:415-44

Mill, J.S. (1843). A System of Logic. London: Longmans, Green and Co.

Minns, Chris \& Rizov, Marian (2005) "The spirit of capitalism? Ethnicity, religion, and selfemployment in early 20th century Canada," Explorations in Economic History, Elsevier, vol. 42(2), pages 259-281, April.

O’Mahony, Mary and Marcel P. Timmer (2009), "Output, Input and Productivity Measures at the Industry Level: the EU KLEMS Database”, Economic Journal, 119(538), pp. F374-F403.

Ozorak, E. W (1989), "Social and Cognitive Influences on the Development of Religious Beliefs and Commitment in Adolescence," Journal for the Scientific Study of Religion 28: 448-463.

Robbins, L. (1945), An Essay on the Nature and Significance of Economic Science. Macmillan and Co., London.

Smith, A. (1904), An Inquiry into the Nature and Causes of the Wealth of Nations. London: Methuen and Co., Ltd., ed. Edwin Cannan. Fifth edition.

Spenkuch, Jörg L. (2011). "The Protestant Ethic and Work: Micro Evidence from Contemporary Germany," MPRA Paper 26444, University Library of Munich, Germany, revised 20 Mar 2011.

Tabellini G. (2005), "Culture and Institutions: Economic Development in the Regions of Europe," Journal of the European Economic Association, forthcoming.

Tabellini G. (2008), "Institutions and Culture," Journal of the European Economic Association Papers and Proceedings, Vol.6(2-3). 
Weber, M. (1904), The Protestant Ethic and the Spirit of Capitalism, Roxbury Publishing Company, reprinted 2001. 


\section{Appendix A - Minorities and networks}

We estimate again equation (11), with the same controls and the same definitions of regions and minority. Outcome variables refer to 1) the number of close friends a) in the workplace, b) who live near the respondent; 2) respondent's participation in voluntary local organization; 3) potential ability to borrow money from relatives and friends in case of need; 4) number of times the respondent has lent money to relatives and friends in the current year; 5) to what extent relatives and friends are sources of information to find a job; 6) how often the respondent help someone to find a job; 7) self-reported general trust in other people; 8) self-reported perception that others' opportunism.

We look at the difference between the coefficients of $m P$ and $m C$. Such difference would indicate to what extent protestant minorities are possibly more socially connected than catholic minorities. Results are reported in Table $\mathrm{A} 1^{28}$.

\section{TABLE A1 AROUND HERE}

\section{Outcomes of Table A1}

Each outcome is based on a precise question of the ISSP Social Networks II survey as detailed below. In italic the question.

1) Thinking about people at your work place, how many of them are close friends of yours? We took the number of friends (between 0 and 60)

2) Thinking now of people who live near you - in your neighborhood or district: How many of these people are close friends of yours? We took the number of friends (between 0 and 90)

28 Minorities are defined over respondents' religion, as information on religious family background is not collected in ISSP Social Network II. 
3) How many other close friends do you have - apart from those at work, in your neighborhood, or family members? Think, for instance, of friends at clubs, church, other like. We took the number of friends (between 0 and 90)

4) People sometimes belong to different kinds of groups or associations. The list below contains different types of groups. For each type of group, please tick a box to say whether you have participated in the activities of this group in the past 12 months. We have derived a dummy variable which takes 1 if the respondent reported to actively participate to church or other religious organization; sports group, hobby or leisure club; charitable organization or group; neighborhood association or group; other associations or groups.

5) Now, suppose you needed to borrow a large sum of money. Who would you turn to first for help? We have derived a dummy variable which takes 1 if the respondent answered one of the following: husband, wife, partner, mother, father, daughter, son, sister, brother, other blood relative, in-law relative, god-parent, close friend, neighbor, someone you work with, employer.

6-7-8) During the past 12 months, how often have you done any of the following things for people you know personally, such as relatives, friends, neighbors or other acquaintances? a) Helped someone outside of your household with housework or shopping b) Lent quite a bit of money to another person; d) Helped somebody to find a job. For all items a) b) and d) we derived a dummy variable which takes 1 if the respondent reported to have helped/lent at least once in the previous 12 months.

9) There are many ways people hear about jobs - from other people, from advertisements or employment agencies, and so on. Please indicate how you first found out about work at our present employer. We have derived a dummy variable which takes 1 if the respondent answered one of the following: from parents, brothers or sisters, from other relatives, from a close friend, from an acquaintance.

10-11) To what extent do you agree or disagree with the following statements? a) There are only a few people I can trust completely; c) If you are not careful, other people will take advantage of you. As regards item a) we derived a dummy variable which takes 1 if the respondent declares to 
disagree or strongly disagree. Regarding item c) we derived a dummy variable which takes 1 if the respondent declares to agree or strongly agree.

\section{Appendix B - ESS Sample}

ESS sample by country and wave is described in Table B1.

\section{Regions and Minorities in ESS data}

In order to identify religious minorities across European regions according to the definitions given above, and to control for unobservable characteristics of geographical areas of residence, we first need to define the level of regional aggregation to apply to our data. Ideally, regions should be comparable in terms of their population and size. The Eurostat NUTS classification provides four level of aggregation: NUTS 0 identify countries; NUTS 1 macro-regions with a population between 3 and 7 million; NUTS 2 regions with a population between 800 thousands and 3 million; NUTS 3 regions (sub-regions in most cases) with a population between 150 thousands and 800 thousands. Unfortunately, not all countries surveyed by the European Social Survey report the same NUTS level, some being more disaggregated (up to level 3) and some being only at level 1. Moreover, in some cases the number of observations at higher NUTS levels is too small to carefully measure the distribution of religious denominations in each region, forcing us to aggregate downwards. Eventually, we have defined four possible definitions of regional unit to apply to our ESS data, according to alternative aggregation criteria:

Region 0 : each country coincides with a region;

Region 1: NUTS 1 whenever possible, NUTS 0 otherwise;

Region 2: NUTS 2 whenever possible, Region 1 aggregation otherwise;

Region 3: NUTS 3 whenever possible, Region 2 aggregation otherwise.

The number of regions in the ESS dataset is 220 under the definition Region 3, 177 under Region 2, 90 under Region 1 and 22 under Region 0. 
Our definition of minority states that a confession $d_{i r}$ of an individual $i$ residing in region $r$ is considered minority if a) its market-share in region $r$ is less than $25 \%$; and b) the marketshare of $d_{i r}$ is the smallest in region $r$. We considered alternative definitions of minority in our analysis. These are: (i) confession $d_{i r}$ of an individual $i$ residing in region $r$ is considered minority if its market-share in region $r$ is less than 25\%; (ii) religion $d_{i r}$ of an individual $i$ residing in region $r$ is considered minority if condition $i$ holds and if $d_{i r}$ is Protestant (resp. Catholic) its market-share is smaller than the share of Catholicism (resp. Protestantism); (iii) religion $d_{i r}$ of an individual $i$ residing in region $r$ is considered minority if the market-share of $d_{i r}$ is the smallest in region $r$.

Our preferred definition is the most stringent, while a priori no clear ranking exists among the other three. In general, these alternative definitions turn out to map to a similar set of regions. Only a few regions in Germany, UK, Sweden and Latvia are affected by the adoption of alternative definitions of minority and only when Protestantism is considered. Instead, the regions reporting Catholic minorities are essentially the same across alternative definitions.

Note that in order to avoid measurement errors we always exclude from our sample regions with less than 50 sampled respondents. However, our results never change if we include all regions.

\section{Appendix C - Religion and risk aversion}

Using SOEP 2004 data, we may define two measures of risk aversion. The first is an index of relative risk aversion (RRA) which can be derived from a question about the amount of windfall money to re-invest in a lottery with specified probabilities and returns, following the procedure indicated in Caliendo et al. (2007). This is an objective measure experimentally validated (Dohmen et al., 2005). The second is the self-reported willingness to take risks measured on a scale from 0 (maximal willingness) to 10 (no willingness). Rather surprisingly the correlation between the two measures is quite small ( 24 percent). The average level of both measures is alike across all confessions (about 2.9 for RRA and 5.6 for the willingness 
to take risk) as well as their standard deviations (1.32 for RRA and 2.30 for willingness), indicating that risk aversion is distributed in a similar way across confessions.

However, a similar marginal distribution can be the resulting outcome of the combined correlation with many variables besides religion. There are two cases to distinguish: if risk aversion is shaped by the religion culture, then the effect of risk aversion on entrepreneurship can be ascribed to the broader effect of religion; if instead risk aversion is a causa prima, then by looking at the relationship between religion and entrepreneurship we could find a spurious correlation. Indeed, we have tested whether risk aversion influences the decision of being religious (i.e. Catholic or Protestant) compared to atheist after controlling for regional (lander) fixed effects, individual age, gender, years of education, marital status, employment condition, and, importantly, father and mother religion. As said, religious family background could influence both the religion and the degree of risk aversion transmitted to children. Estimates of a probit model are reported in the first column of Table C1. By using RRA we cannot reject the hypothesis that risk aversion is uncorrelated with religiosity. Instead, when willingness to take risks is considered, the model suggests that more risk averse people are more likely to be religious. Furthermore, we test whether the degree of risk aversion is correlated with the particular individual confession. We have estimated a multinomial probit model where the dependent variable is individual confession (Atheist - the base outcome - , Catholic and Protestant), and the explanatory variables are the measures of risk aversion and the same controls used above. Coefficients of the two measures of risk aversion for both Catholic and Protestant outcomes are reported in columns 2 and 3 of Table C1. Their difference is in column 4. Regardless of the measure adopted, risk aversion influences the probability of being Catholic or Protestant to a similar extent.

\section{TABLE C1 AROUND HERE}




\section{Figures}

\section{Figure 1}

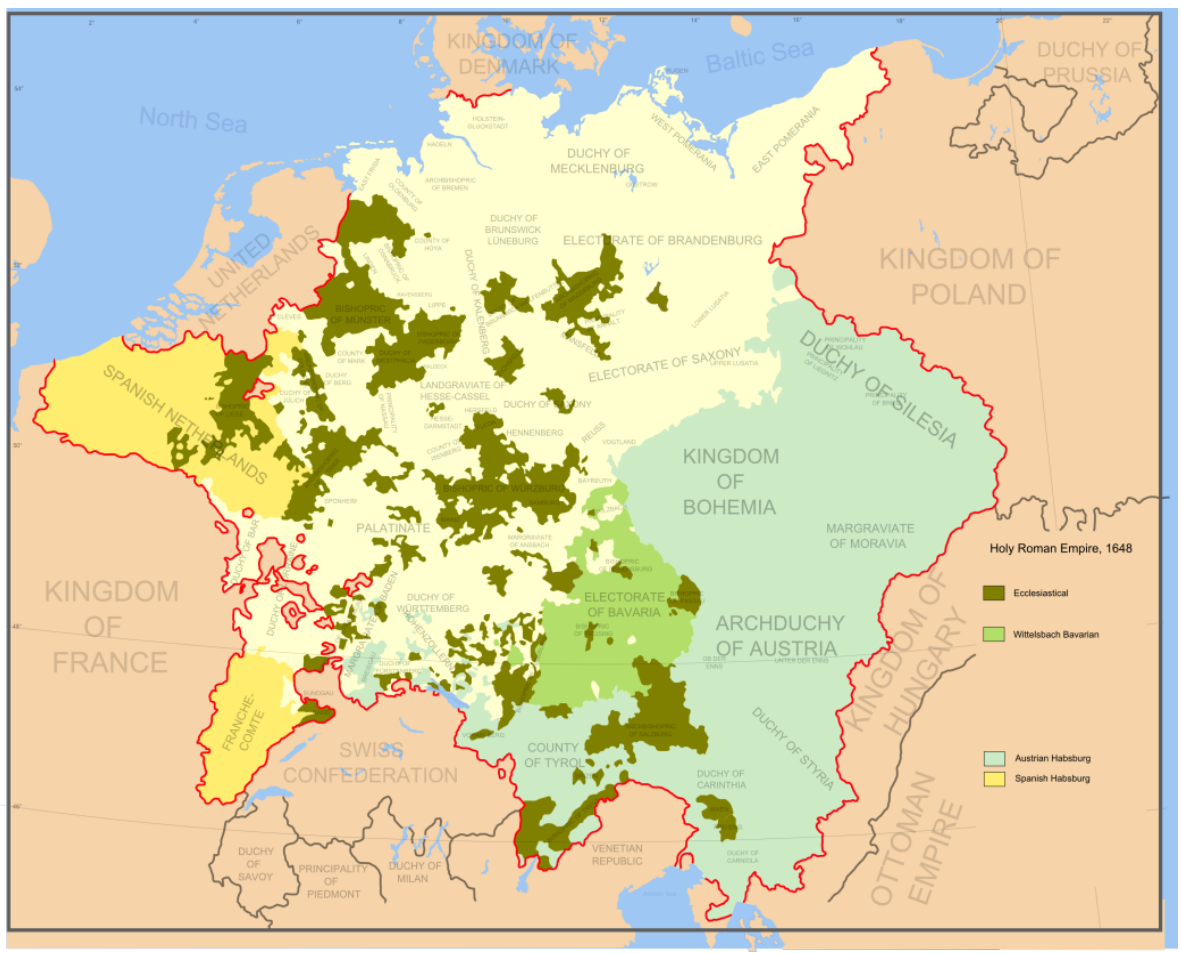

Source: Made from the public domain map "Central Europe about 1648" from the Historical Atlas by William R. Shepherd, at the Perry-Castañeda Library Map Collection at the University of Texas. 
Figure 2: Catholics as percentage of residents in Central Europe.

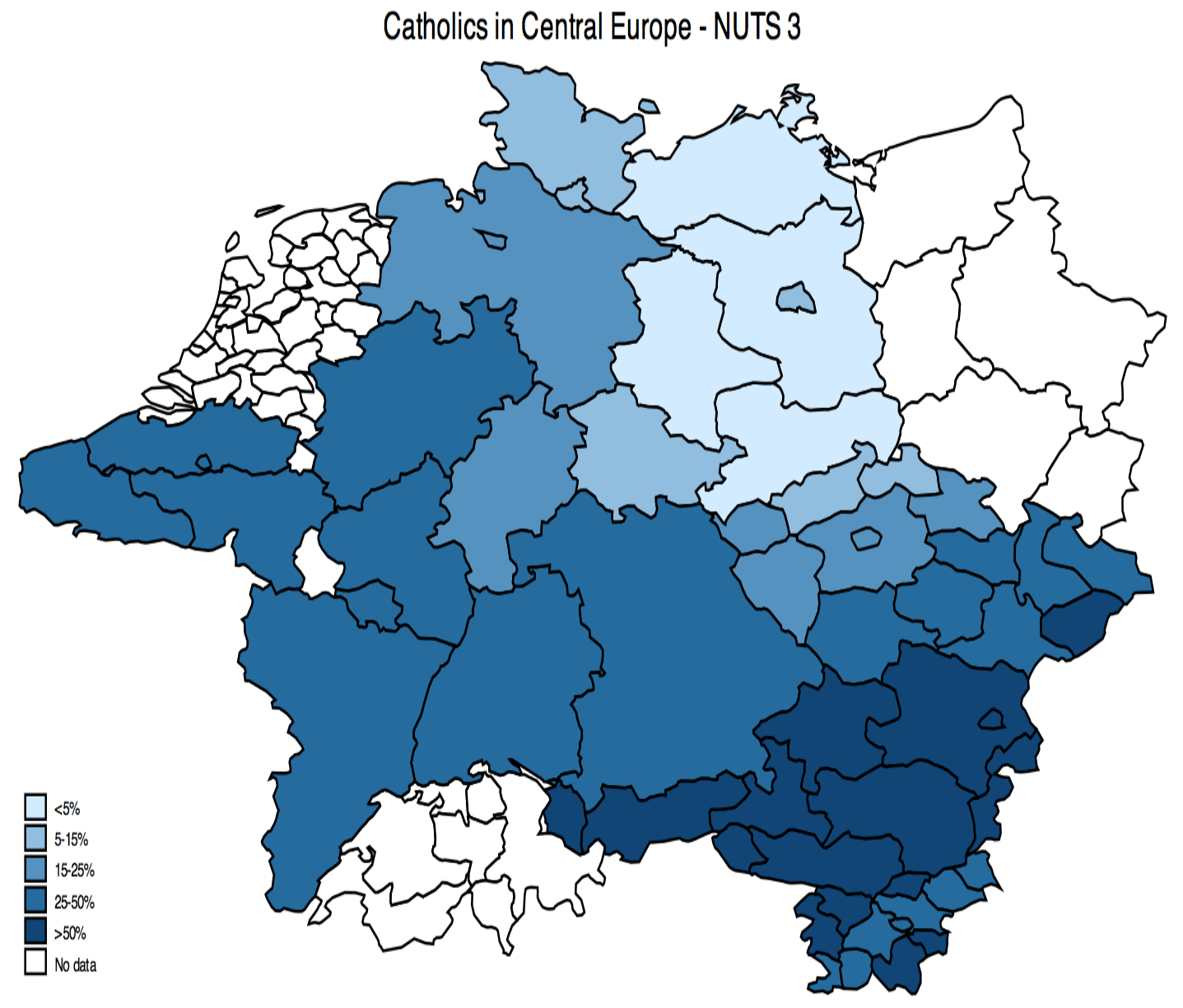

Source: our elaboration on ESS data 
Figure 3. Atheism, Religiousness and degree of adhesion

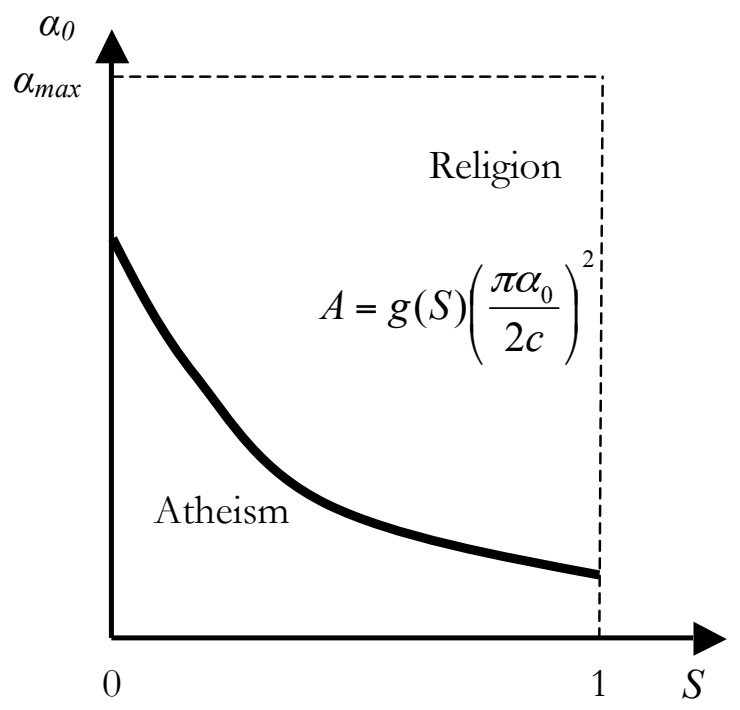


Figure 4

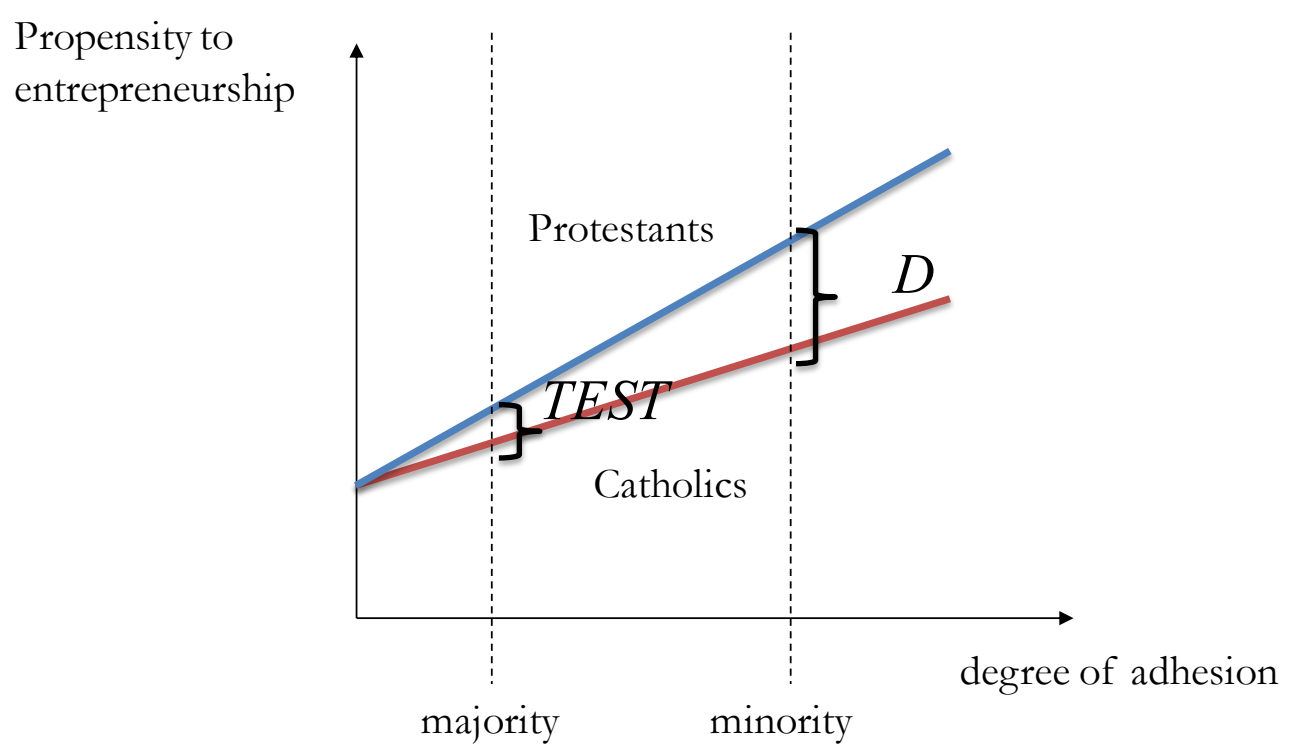


Figure 5:

\section{Catholics as \% of resident population in Europe}

ESS, 2002-2008, NUTS 2

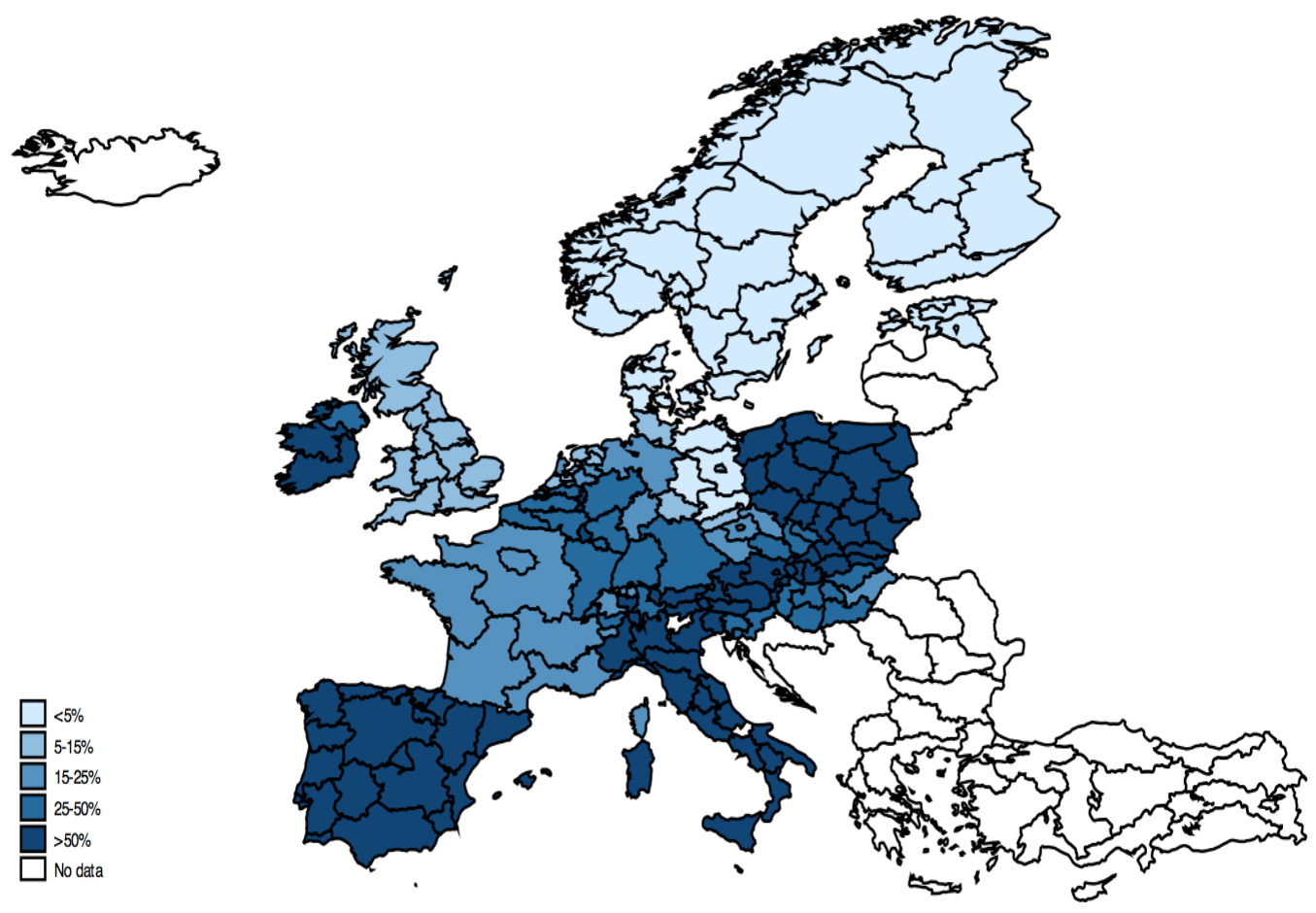


Figure 6:

\section{Protestants as $\%$ of resident population in Europe}

ESS, 2002-2008, NUTS 2

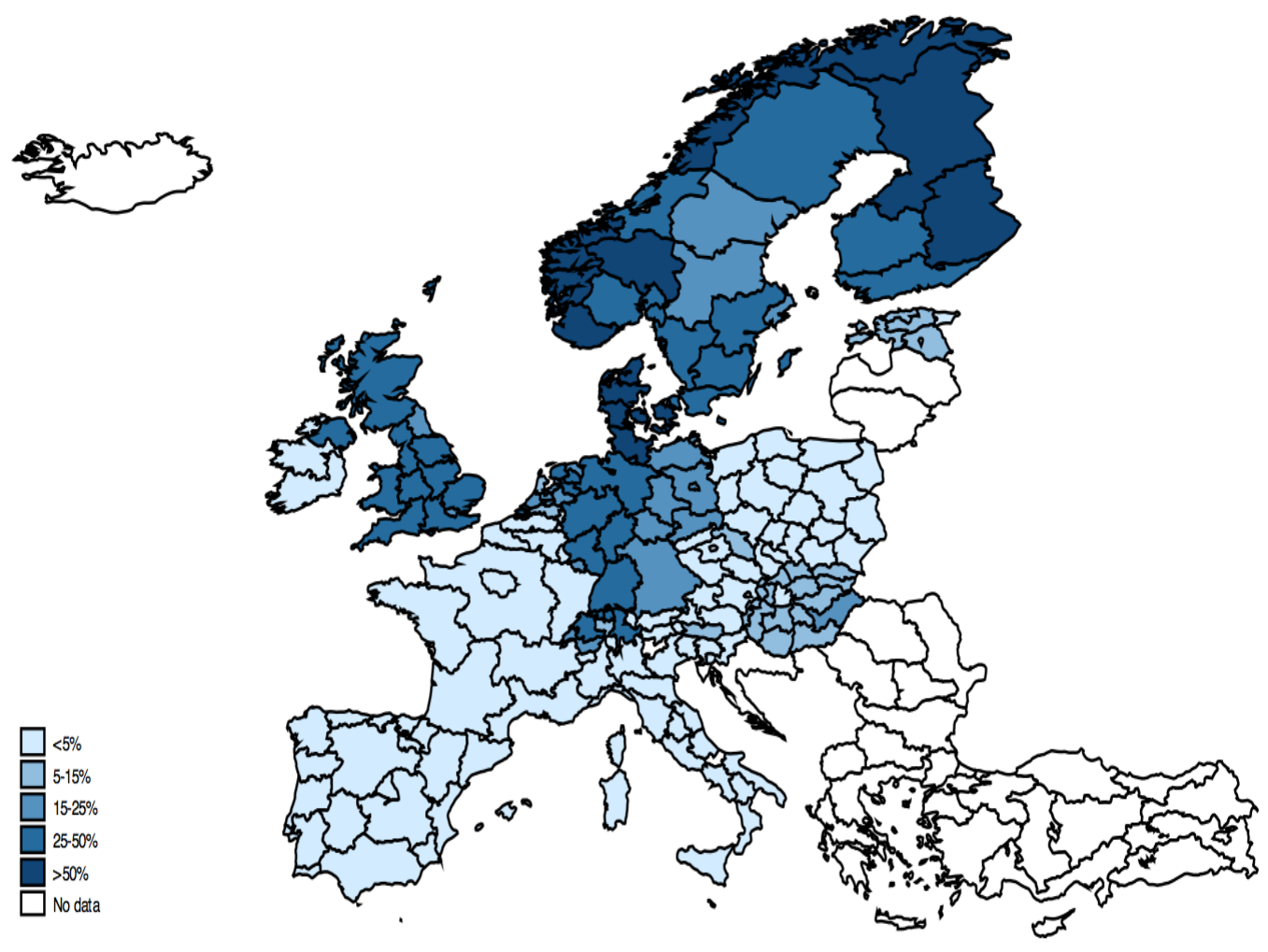


Figure 7:

Atheists as $\%$ of resident population in Europe

ESS, 2002-2008, NUTS 2

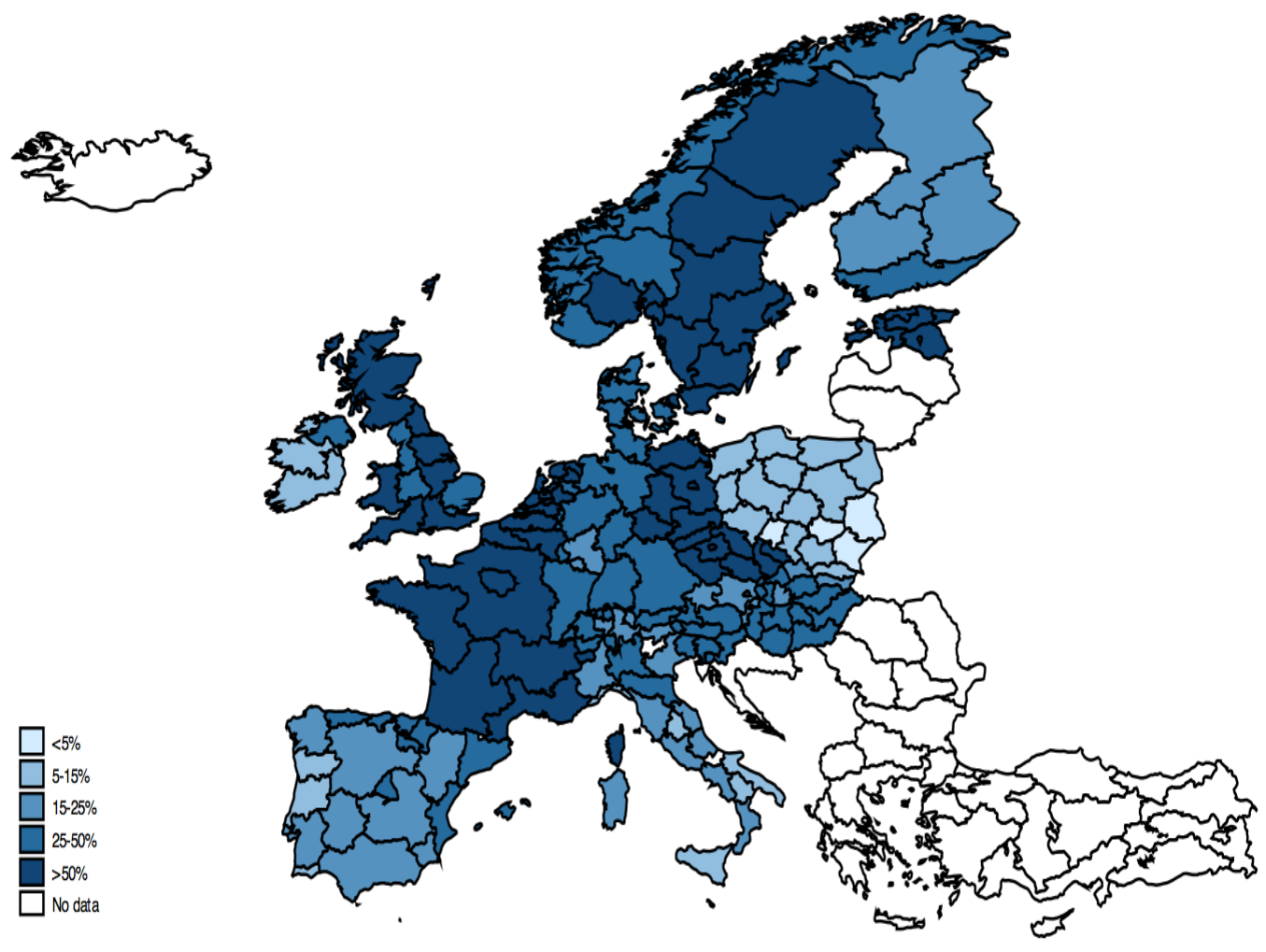


Figure 8: Protestant minorities - ESS data

\section{Minority Protestants - NUTS 2}

ESS, 2002-2008, NUTS2
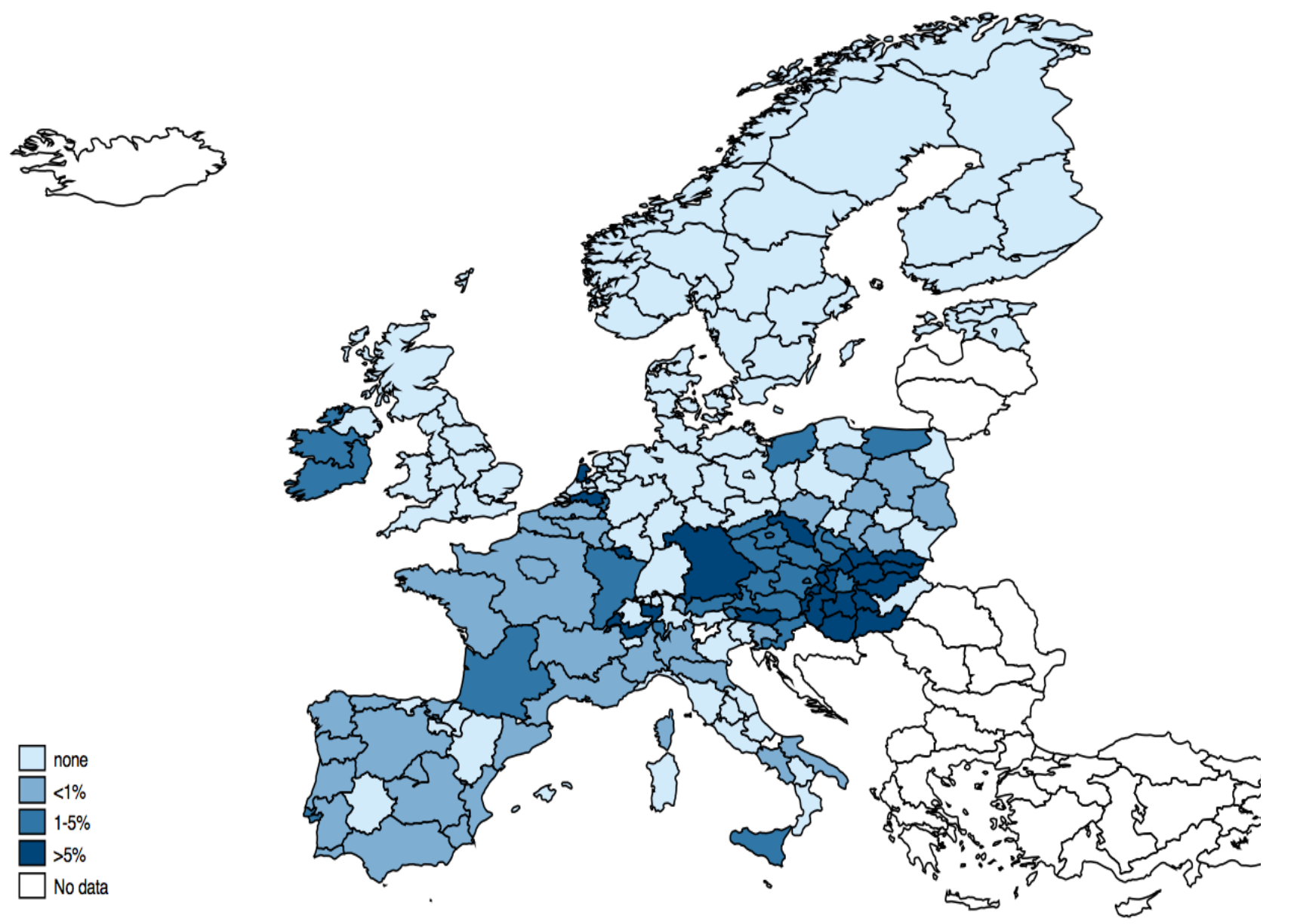
Figure 9: Catholic minorities - ESS data

Minority Catholics as \% of resident population ESS, 2002-2008, NUTS 2
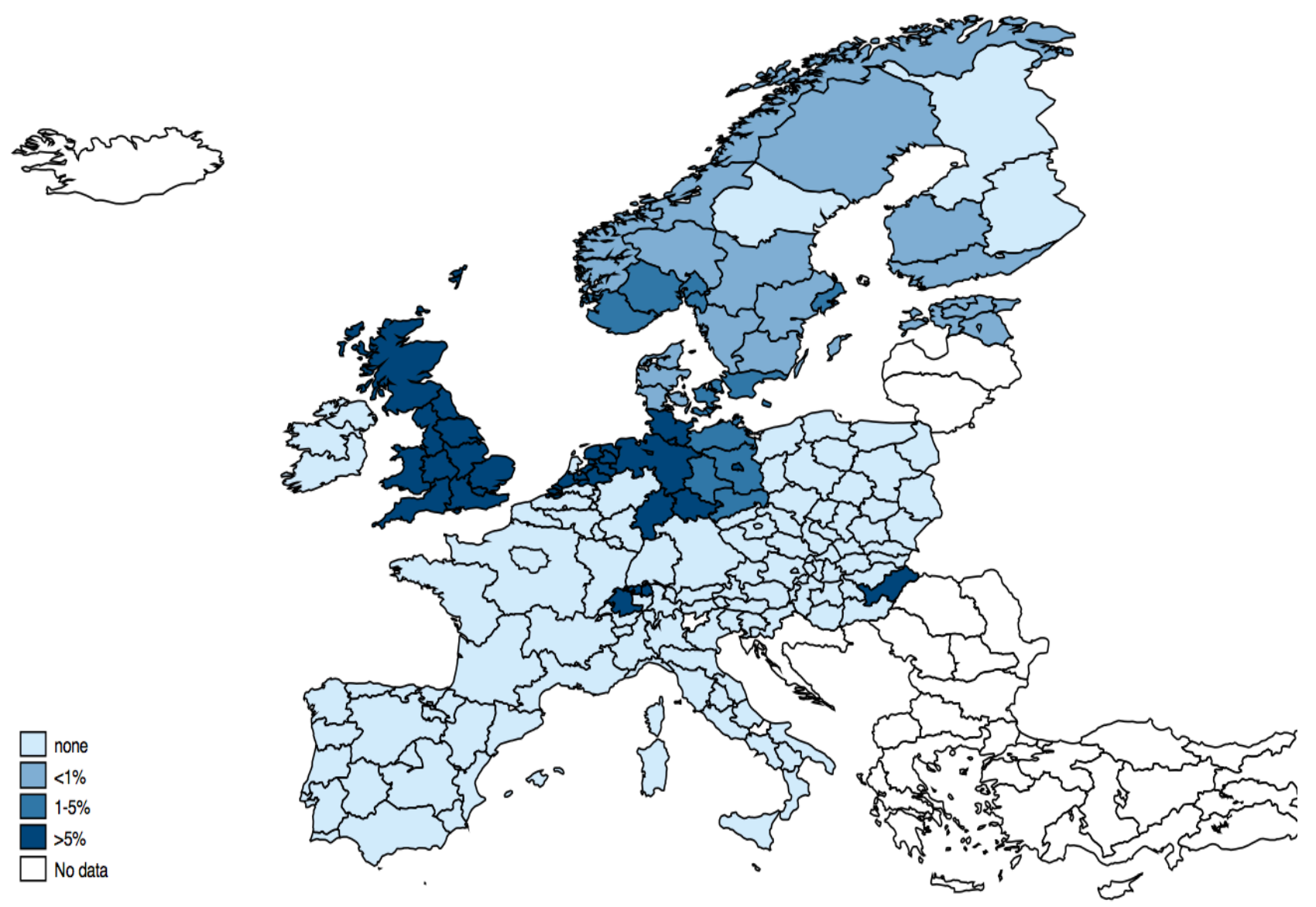
Figure 10: Proportion of self-employed - ESS data

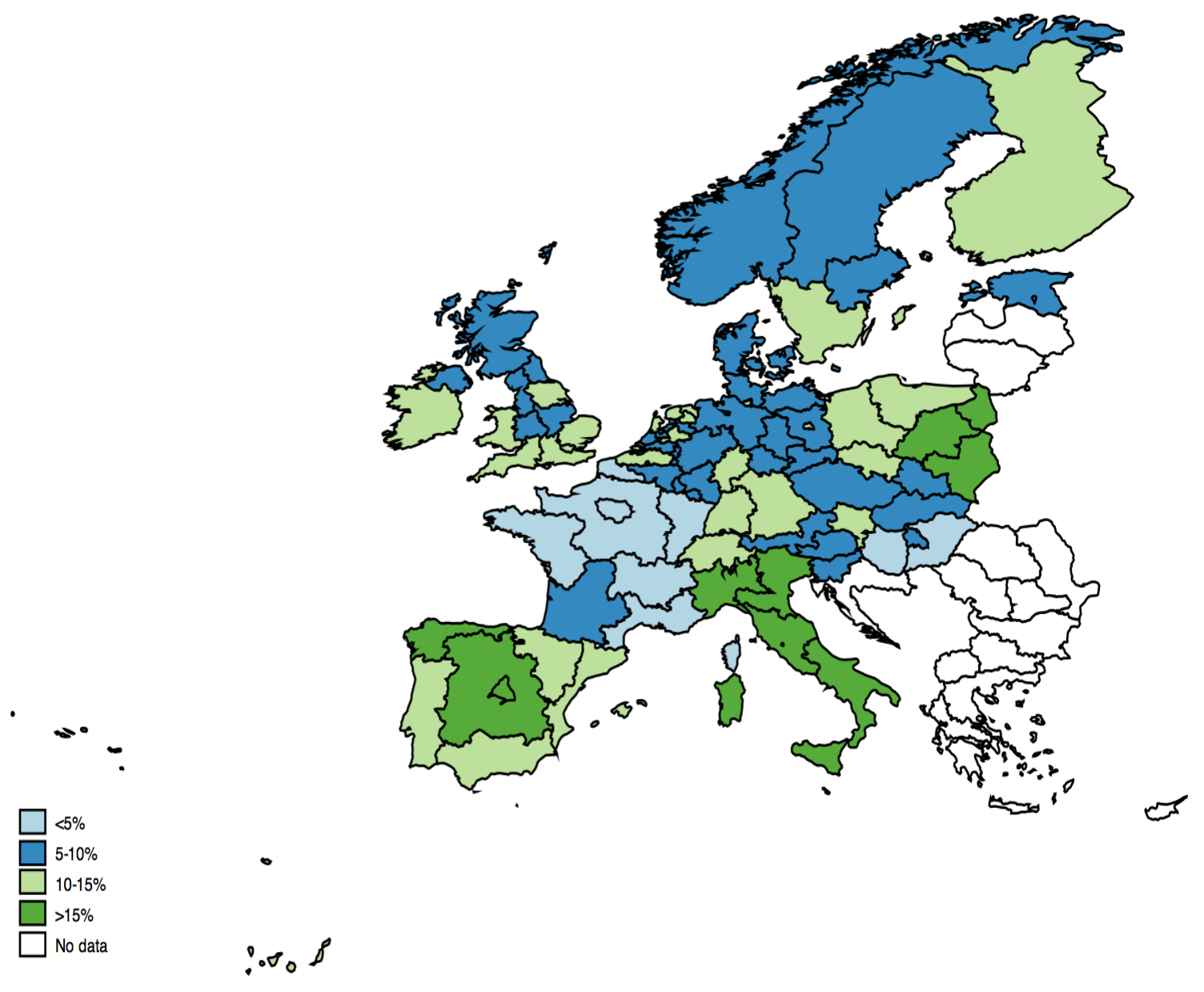


Figure 11: Percentages of self-employed individuals (total, with employees, with at least 10 employees)

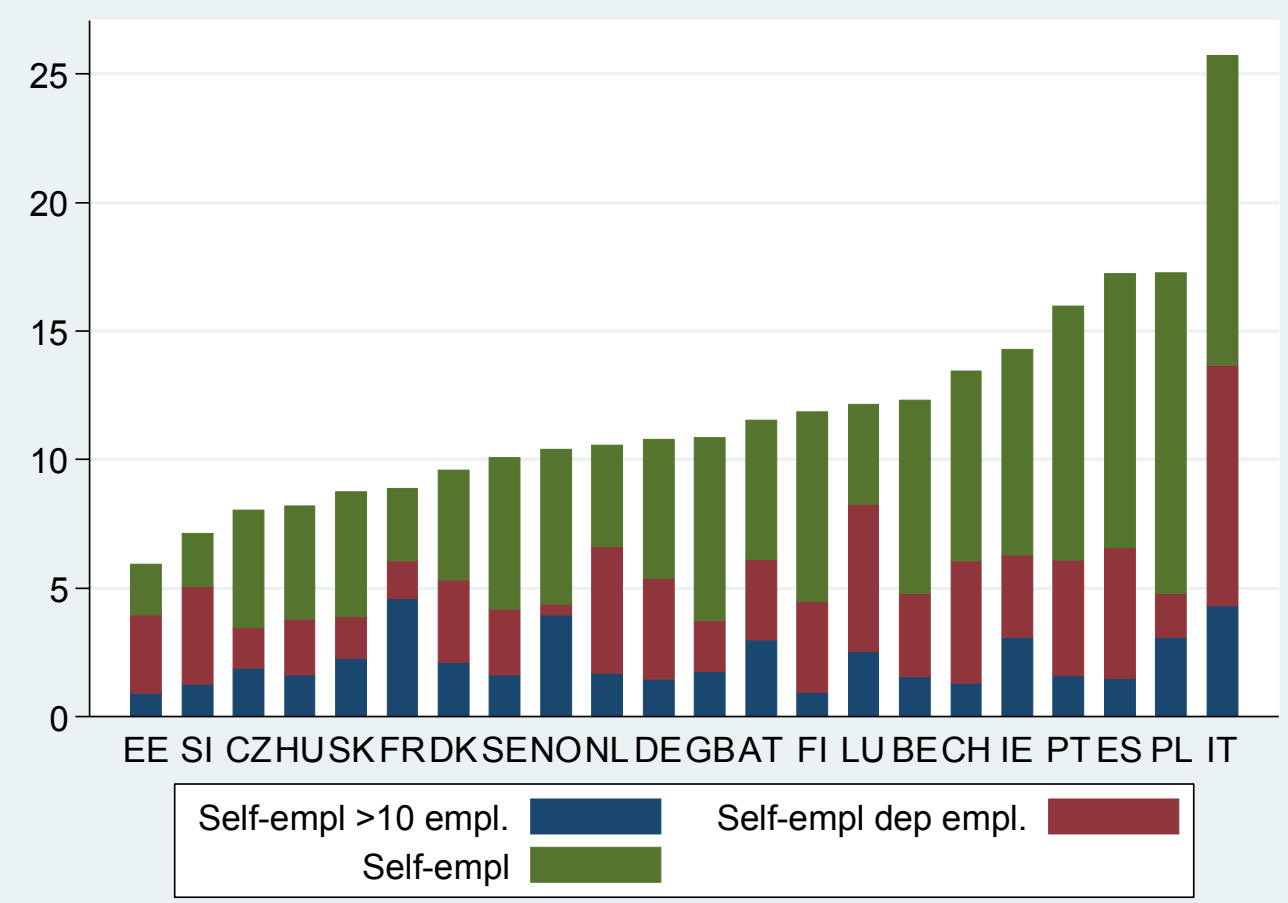

Source: European Social Survey 2002-2008 


\section{Tables}

Table 1: Correspondence between modern German Catholic dioceses and religious distribution in 1618

\begin{tabular}{|c|c|c|c|c|c|c|}
\hline & $\begin{array}{l}\text { Populati } \\
\text { on } 2009\end{array}$ & $\begin{array}{l}\text { Catholic } \\
\text { s } 2009\end{array}$ & $\begin{array}{l}\text { proporti } \\
\text { on } \\
\text { Catholic }\end{array}$ & \multicolumn{2}{|c|}{$\begin{array}{l}\text { territories of } 1618 \text { totally } \\
\text { or partially included in the } \\
\text { current catholic bishopric }\end{array}$} & \multirow{2}{*}{$\begin{array}{l}\text { Importa } \\
\text { nce of } \\
\text { protest } \\
\text { ant } \\
\text { territori } \\
\text { es in } \\
1618 \\
\end{array}$} \\
\hline & & & & Catholic & Protestant & \\
\hline $\begin{array}{l}\text { Church province of } \\
\text { Bamberg }\end{array}$ & 5.589 & 2.560 & 46 & & & \\
\hline $\begin{array}{l}\text { Archdiocese of } \\
\text { Bamberg }\end{array}$ & 2.077 & 727 & 35 & $\begin{array}{l}\text { Bishopric } \\
\text { of } \\
\text { Bamberg }\end{array}$ & $\begin{array}{l}\text { Ansbach, } \\
\text { Bayreuth }\end{array}$ & 2 \\
\hline Diocese of Eichstätt & 870 & 424 & 49 & $\begin{array}{l}\text { Bishopric } \\
\text { of } \\
\text { Eichstätt }\end{array}$ & Ansbach & 3 \\
\hline Diocese of Würzburg & 1.334 & 829 & 62 & $\begin{array}{l}\text { Bishopric } \\
\text { Wurzbur } \\
\mathrm{g} \text { and } \\
\text { Bishopric } \\
\text { of Mainz }\end{array}$ & $\begin{array}{l}\text { (Protestant } \\
\text { territories all } \\
\text { around) }\end{array}$ & 4 \\
\hline $\begin{array}{l}\text { Church province of } \\
\text { Berlin }\end{array}$ & 10.682 & 563 & 5 & & & \\
\hline Archdiocese of Berlin & 5.811 & 393 & 7 & & Brandeburg & 1 \\
\hline $\begin{array}{l}\text { Diocese of Dresden- } \\
\text { Meißen }\end{array}$ & 4.155 & 141 & 3 & & Saxony & 1 \\
\hline Diocese of Görlitz & 716 & 29 & 4 & & Saxony & 1 \\
\hline $\begin{array}{l}\text { Church province of } \\
\text { Freiburg }\end{array}$ & 13.027 & 4.694 & 36 & & & \\
\hline $\begin{array}{l}\text { Archdiocese of } \\
\text { Freiburg }\end{array}$ & 5.203 & 2.006 & 39 & $\begin{array}{l}\text { Breisgau, } \\
\text { Bishopric } \\
\text { of } \\
\text { Strasbour }\end{array}$ & $\begin{array}{l}\text { Baden-Baden, } \\
\text { Baden- } \\
\text { Durlach, } \\
\text { Wurttemberg }\end{array}$ & 3 \\
\hline
\end{tabular}




\begin{tabular}{|c|c|c|c|c|c|c|}
\hline & & & & $\mathrm{g}$ & & \\
\hline Diocese of Mainz & 2.824 & 767 & 27 & $\begin{array}{l}\text { Archbish } \\
\text { opric of } \\
\text { Mainz }\end{array}$ & $\begin{array}{l}\text { Electoral } \\
\text { Palatinate } \\
\text { (Calvinism), } \\
\text { Hessen- } \\
\text { Darmstadt }\end{array}$ & 2 \\
\hline $\begin{array}{l}\text { Diocese of Rottenburg- } \\
\text { Stuttgart }\end{array}$ & 5.000 & 1.921 & 38 & $\begin{array}{l}\text { Hohenzol } \\
\text { lern and } \\
\text { other } \\
\text { small } \\
\text { fiefs at } \\
\text { the } \\
\text { border } \\
\text { with } \\
\text { Switzerla } \\
\text { nd }\end{array}$ & Wurttemberg & 2 \\
\hline $\begin{array}{l}\text { Church province of } \\
\text { Hamburg }\end{array}$ & 13.342 & 1.591 & 12 & & & \\
\hline $\begin{array}{l}\text { Archdiocese of } \\
\text { Hamburg }\end{array}$ & 5.787 & 389 & 7 & & $\begin{array}{l}\text { Mecklenburg, } \\
\text { Lauenburg, } \\
\text { Holstein }\end{array}$ & 1 \\
\hline Diocese of Hildesheim & 5.400 & 627 & 12 & $\begin{array}{l}\text { bishopric } \\
\text { of } \\
\text { Hildeshei } \\
\text { m }\end{array}$ & $\begin{array}{l}\text { Luneburg, } \\
\text { Brunschweig, } \\
\text { Hessen-Kassel }\end{array}$ & 1 \\
\hline Diocese of Osnabrück & 2.155 & 575 & 27 & $\begin{array}{l}\text { bishopric } \\
\text { Osnabruc } \\
\text { k }\end{array}$ & $\begin{array}{l}\text { Bremen, } \\
\text { Lingen, } \\
\text { Hessen-Kassel }\end{array}$ & 2 \\
\hline $\begin{array}{l}\text { Church province of } \\
\text { Köln }\end{array}$ & 18.895 & 8.286 & 44 & & & \\
\hline Archdiocese of Köln & 5.200 & 2.111 & 41 & $\begin{array}{l}\text { bishopric } \\
\text { of Koln, } \\
\text { mixed }\end{array}$ & mixed & 3 \\
\hline Diocese of Aachen & 2.038 & 1.137 & 56 & Julich & Koln & 4 \\
\hline Diocese of Essen & 2.557 & 880 & 34 & $\begin{array}{l}\text { Essen } \\
\text { Abbey, } \\
\text { Berg }\end{array}$ & Mark & 3 \\
\hline Diocese of Limburg & 2.358 & 663 & 28 & Sayn & $\begin{array}{l}\text { Nassau, } \\
\text { Hessen- } \\
\text { Darmstadt }\end{array}$ & 2 \\
\hline Diocese of Münster & 4.274 & 1.991 & 47 & $\begin{array}{l}\text { bishopric } \\
\text { of } \\
\text { Munster }\end{array}$ & $\begin{array}{l}\text { Oldenburg, } \\
\text { Mark }\end{array}$ & 4 \\
\hline Diocese of Trier & 2.468 & 1.504 & 61 & $\begin{array}{l}\text { archbisho } \\
\text { pric of } \\
\text { Trier }\end{array}$ & & 4 \\
\hline $\begin{array}{l}\text { Church province of } \\
\text { München u. Freising }\end{array}$ & 7.813 & 4.914 & 63 & & & \\
\hline
\end{tabular}




\begin{tabular}{|c|c|c|c|c|c|c|}
\hline $\begin{array}{l}\text { Archdiocese of } \\
\text { München und Freising }\end{array}$ & 3.552 & 1.787 & 50 & $\begin{array}{l}\text { Bishopric } \\
\text { of } \\
\text { Freising, } \\
\text { Bavaria }\end{array}$ & & 5 \\
\hline Diocese of Augsburg & 2.298 & 1.377 & 60 & $\begin{array}{l}\text { Bishopric } \\
\text { of } \\
\text { Augsburg }\end{array}$ & $\begin{array}{l}\text { Cities of } \\
\text { Augsburg, } \\
\text { Kepten, } \\
\text { Memmingen, } \\
\text { Lindau }\end{array}$ & 4 \\
\hline Diocese of Regensburg & 1.404 & 1.255 & 89 & $\begin{array}{l}\text { Bishopric } \\
\text { of } \\
\text { Regensbu } \\
\text { rg, } \\
\text { Bavaria }\end{array}$ & $\begin{array}{l}\text { City of } \\
\text { Regensburg }\end{array}$ & 5 \\
\hline Diocese of Passau & 559 & 495 & 89 & $\begin{array}{l}\text { Bishopric } \\
\text { of Passau }\end{array}$ & & 5 \\
\hline $\begin{array}{l}\text { Church province of } \\
\text { Paderborn }\end{array}$ & 12.147 & 2.302 & 19 & & & \\
\hline $\begin{array}{l}\text { Archdiocese of } \\
\text { Paderborn }\end{array}$ & 4.900 & 1.643 & 34 & $\begin{array}{l}\text { bishopric } \\
\text { of } \\
\text { Paderbor } \\
\text { n, } \\
\text { Westphal } \\
\text { ia }\end{array}$ & $\begin{array}{l}\text { Ravensberg, } \\
\text { Lippe, } \\
\text { Schaumburg, } \\
\text { Waldek }\end{array}$ & 3 \\
\hline Diocese of Fulda & 2.297 & 413 & 18 & $\begin{array}{l}\text { Fulda } \\
\text { Abbey }\end{array}$ & $\begin{array}{l}\text { Hessen-Kassel, } \\
\text { Hessen- } \\
\text { Darmstadt }\end{array}$ & 2 \\
\hline Diocese of Erfurt & 2.250 & 156 & 7 & & $\begin{array}{l}\text { Sachsen } \\
\text { Herzogtumer, } \\
\text { Schwarzburg }\end{array}$ & 1 \\
\hline Diocese of Magdeburg & 2.700 & 90 & 3 & & Magdeburg & 1 \\
\hline
\end{tabular}

Source: Columns (1)-(3) from German Bishops' Conference data; Historical Atlas by William R. Shepherd, 1923. Importance of 1618 protestant territories is defined as: $1=$ largely dominant, $2=$ larger than catholic territories, $3=$ smaller than catholic territories but sizeable, $4=$ much smaller than catholic territories, $5=$ very small 
Table 2. Adhesion to religion and religious norms among minorities.

\begin{tabular}{|c|c|c|c|c|c|c|c|c|c|}
\hline & $\begin{array}{c}\text { (1) } \\
\text { Number of } \\
\text { times pray } \\
\text { per week }\end{array}$ & $\begin{array}{c}\text { (2) } \\
\text { Regular } \\
\text { praying }\end{array}$ & $\begin{array}{c}(3) \\
\text { Religiousnes } \\
\text { s }\end{array}$ & $\begin{array}{c}\text { (4) } \\
\text { My way }\end{array}$ & $\begin{array}{c}(5) \\
\text { Fate }\end{array}$ & $\begin{array}{c}\text { (6) } \\
\text { Afterlife }\end{array}$ & $\begin{array}{c}(7) \\
\text { Heaven }\end{array}$ & $\begin{array}{c}(8) \\
\text { Hell }\end{array}$ & $\begin{array}{c}(9) \\
\text { Confidence } \\
\text { in church } \\
\text { and rel. } \\
\text { organizations } \\
\end{array}$ \\
\hline Protestant & $\begin{array}{c}0.681 * * * \\
(0.262)\end{array}$ & $\begin{array}{l}-0.0386 \\
(0.0296)\end{array}$ & $\begin{array}{c}-0.0641 * * \\
(0.0300)\end{array}$ & $\begin{array}{l}-0.0323 \\
(0.0333)\end{array}$ & $\begin{array}{l}-0.0189 \\
(0.0252)\end{array}$ & $\begin{array}{l}-0.0375 \\
(0.0327)\end{array}$ & $\begin{array}{l}-0.0486 \\
(0.0323)\end{array}$ & $\begin{array}{l}-0.0250 \\
(0.0312)\end{array}$ & $\begin{array}{l}-0.0138 \\
(0.0275)\end{array}$ \\
\hline Minority Protestant & $\begin{array}{c}0.922 * * \\
(0.427)\end{array}$ & $\begin{array}{c}0.170 * * * \\
(0.0464)\end{array}$ & $\begin{array}{c}0.236 * * * \\
(0.0475)\end{array}$ & $\begin{array}{l}0.120^{* *} \\
(0.0489)\end{array}$ & $\begin{array}{c}0.0176 \\
(0.0397)\end{array}$ & $\begin{array}{c}0.142 * * * \\
(0.0495)\end{array}$ & $\begin{array}{l}0.168^{* * *} \\
(0.0506)\end{array}$ & $\begin{array}{l}0.130 * * \\
(0.0507)\end{array}$ & $\begin{array}{l}0.0867^{*} \\
(0.0467)\end{array}$ \\
\hline Minority Catholic & $\begin{array}{c}1.685^{* * *} \\
(0.535)\end{array}$ & $\begin{array}{c}0.247 * * * \\
(0.0694)\end{array}$ & $\begin{array}{c}0.141 * \\
(0.0744)\end{array}$ & $\begin{array}{c}0.0622 \\
(0.0765)\end{array}$ & $\begin{array}{c}-0.204 * * * \\
(0.0720)\end{array}$ & $\begin{array}{c}0.310^{* * *} \\
(0.0639)\end{array}$ & $\begin{array}{c}0.150^{*} \\
(0.0833)\end{array}$ & $\begin{array}{c}0.218^{* * *} \\
(0.0843)\end{array}$ & $\begin{array}{l}0.155^{* *} \\
(0.0749)\end{array}$ \\
\hline Constant & $\begin{array}{c}0.168 \\
(0.562)\end{array}$ & $\begin{array}{l}0.165^{* *} \\
(0.0725)\end{array}$ & $\begin{array}{c}0.342^{* * *} \\
(0.0725)\end{array}$ & $\begin{array}{c}0.459 * * * \\
(0.0781)\end{array}$ & $\begin{array}{c}0.598 * * * \\
(0.0623)\end{array}$ & $\begin{array}{c}0.602 * * * \\
(0.0769)\end{array}$ & $\begin{array}{c}0.548^{* * *} \\
(0.0777)\end{array}$ & $\begin{array}{c}0.500 * * * \\
(0.0752)\end{array}$ & $\begin{array}{c}0.237 * * * \\
(0.0670)\end{array}$ \\
\hline $\begin{array}{l}\text { Observations } \\
\text { R-squared }\end{array}$ & $\begin{array}{c}12,869 \\
0.193\end{array}$ & $\begin{array}{c}12,869 \\
0.188\end{array}$ & $\begin{array}{c}12,896 \\
0.146\end{array}$ & $\begin{array}{c}12,268 \\
0.062\end{array}$ & $\begin{array}{c}13,179 \\
0.055\end{array}$ & $\begin{array}{c}11,669 \\
0.108\end{array}$ & $\begin{array}{c}11,566 \\
0.141\end{array}$ & $\begin{array}{c}11,397 \\
0.122\end{array}$ & $\begin{array}{c}12,614 \\
0.066\end{array}$ \\
\hline
\end{tabular}

Note: OLS Linear Probability Model estimates of equation (1) on ISSP Religion III data. Robust standard errors in parenthesis. Sample includes only Protestant and Catholics. Gender, age, years of education, urban or rural residence, parents religion and regional fixed effects (NUTS 1) are included as controls. Countries included: Austria, Belgium, Czech Republic, Denmark, Finland, France, Germany, Ireland, Latvia, Netherlands, Norway, Slovak Republic, Slovenia, Spain, Sweden, Switzerland. 
Table 3: Proportions of Catholics, Protestants and Atheists in each country

\begin{tabular}{|c|c|c|c|}
\hline country & catholic & protestant & atheist \\
\hline $\mathrm{AT}$ & 0.66 & 0.04 & 0.30 \\
\hline $\mathrm{BE}$ & 0.42 & 0.01 & 0.57 \\
\hline $\mathrm{CH}$ & 0.33 & 0.32 & 0.34 \\
\hline $\mathrm{CZ}$ & 0.26 & 0.03 & 0.71 \\
\hline $\mathrm{DE}$ & 0.23 & 0.29 & 0.47 \\
\hline DK & 0.01 & 0.59 & 0.41 \\
\hline $\mathrm{EE}$ & 0.01 & 0.10 & 0.90 \\
\hline ES & 0.72 & 0.00 & 0.28 \\
\hline FI & 0.00 & 0.65 & 0.35 \\
\hline FR & 0.31 & 0.01 & 0.68 \\
\hline GB & 0.11 & 0.32 & 0.57 \\
\hline $\mathrm{HU}$ & 0.39 & 0.15 & 0.46 \\
\hline $\mathrm{IE}$ & 0.81 & 0.03 & 0.16 \\
\hline IT & 0.79 & 0.00 & 0.21 \\
\hline $\mathrm{LU}$ & 0.65 & 0.01 & 0.34 \\
\hline NL & 0.22 & 0.17 & 0.61 \\
\hline $\mathrm{NO}$ & 0.01 & 0.49 & 0.50 \\
\hline PL & 0.92 & 0.00 & 0.08 \\
\hline PT & 0.85 & 0.01 & 0.14 \\
\hline SE & 0.01 & 0.27 & 0.72 \\
\hline SI & 0.53 & 0.01 & 0.46 \\
\hline SK & 0.67 & 0.08 & 0.25 \\
\hline Average & 0.39 & 0.18 & 0.43 \\
\hline
\end{tabular}

Note that countries are indicated by their ISO code, i.e. :

Austria AT Italy IT Belgium BE Luxembourg LU Czech Republic CZ Netherlands NL Denmark DK Norway NO Estonia EE Poland PL Finland FI Portugal PT France FR Slovakia SK Germany DE Slovenia SI Spain ES Hungary HU Sweden SE Iceland IS Switzerland CH Ireland IE United Kingdom GB. 
Table 4: Proportions of self-employed individuals (total, with employees, with at least 10 employees)

\begin{tabular}{|c|c|c|c|}
\hline country & selfemployed & $\begin{array}{l}\text { selfemployed } \\
\text { with } \\
\text { employees }\end{array}$ & $\begin{array}{l}\text { selfemployed } \\
\text { with more } \\
\text { than } 10 \\
\text { employees }\end{array}$ \\
\hline $\mathrm{AT}$ & 0.103 & 0.055 & 0.027 \\
\hline $\mathrm{BE}$ & 0.106 & 0.041 & 0.013 \\
\hline $\mathrm{CH}$ & 0.127 & 0.057 & 0.012 \\
\hline $\mathrm{CZ}$ & 0.073 & 0.032 & 0.017 \\
\hline $\mathrm{DE}$ & 0.098 & 0.049 & 0.013 \\
\hline DK & 0.092 & 0.051 & 0.020 \\
\hline $\mathrm{EE}$ & 0.054 & 0.036 & 0.008 \\
\hline ES & 0.141 & 0.054 & 0.012 \\
\hline FI & 0.114 & 0.043 & 0.009 \\
\hline FR & 0.056 & 0.038 & 0.029 \\
\hline GB & 0.104 & 0.036 & 0.017 \\
\hline $\mathrm{HU}$ & 0.050 & 0.023 & 0.010 \\
\hline IE & 0.127 & 0.056 & 0.027 \\
\hline IT & 0.197 & 0.105 & 0.033 \\
\hline LU & 0.097 & 0.066 & 0.020 \\
\hline NL & 0.099 & 0.062 & 0.016 \\
\hline NO & 0.101 & 0.042 & 0.038 \\
\hline PL & 0.149 & 0.041 & 0.026 \\
\hline PT & 0.132 & 0.050 & 0.013 \\
\hline SE & 0.096 & 0.040 & 0.015 \\
\hline SI & 0.059 & 0.042 & 0.011 \\
\hline SK & 0.076 & 0.034 & 0.020 \\
\hline Total & 0.102 & 0.046 & 0.018 \\
\hline
\end{tabular}


Table 5 - Panel A: Religious denomination and the propensity of being entrepreneur

\begin{tabular}{|c|c|c|c|}
\hline VARIABLES & $\begin{array}{c}1) \\
\text { selfemplACT }\end{array}$ & $\begin{array}{c}(2) \\
\text { selfemplACT }\end{array}$ & $\begin{array}{c}\text { (3) } \\
\text { selfemplACT }\end{array}$ \\
\hline PROTESTANT & $\begin{array}{l}-0.003 \\
(0.008)\end{array}$ & $\begin{array}{l}-0.003 \\
(0.008)\end{array}$ & $\begin{array}{l}-0.002 \\
(0.008)\end{array}$ \\
\hline MINORITY & $\begin{array}{c}0.007 \\
(0.012)\end{array}$ & $\begin{array}{c}0.007 \\
(0.012)\end{array}$ & $\begin{array}{c}0.007 \\
(0.013)\end{array}$ \\
\hline MAJORITY & $\begin{array}{l}-0.003 \\
(0.010)\end{array}$ & $\begin{array}{l}-0.002 \\
(0.010)\end{array}$ & $\begin{array}{c}0.004 \\
(0.009)\end{array}$ \\
\hline PROTESTANT*MAJ. & $\begin{array}{c}0.019 \\
(0.015)\end{array}$ & $\begin{array}{c}0.019 \\
(0.015)\end{array}$ & $\begin{array}{c}0.013 \\
(0.014)\end{array}$ \\
\hline PROTESTANT*MIN. & $\begin{array}{c}0.036^{* * * *} \\
(0.011)\end{array}$ & $\begin{array}{c}0.035^{* * * *} \\
(0.012)\end{array}$ & $\begin{array}{c}0.034^{* * *} * \\
(0.012)\end{array}$ \\
\hline FOREIGN & $\begin{array}{l}-0.017 \\
(0.016)\end{array}$ & $\begin{array}{l}-0.015 \\
(0.016)\end{array}$ & $\begin{array}{l}-0.017 \\
(0.016)\end{array}$ \\
\hline AGE & $\begin{array}{c}0.004^{* * *} \\
(0.000)\end{array}$ & $\begin{array}{c}0.004 * * * \\
(0.000)\end{array}$ & $\begin{array}{c}0.004 * * * \\
(0.000)\end{array}$ \\
\hline MALE & $\begin{array}{c}0.086^{* * *} \\
(0.007)\end{array}$ & $\begin{array}{c}0.087 * * * \\
(0.007)\end{array}$ & $\begin{array}{c}0.086^{* * * *} \\
(0.007)\end{array}$ \\
\hline FATHER SELF EMP. & $\begin{array}{c}0.132^{* * *} \\
(0.007)\end{array}$ & $\begin{array}{c}0.132 * * * \\
(0.007)\end{array}$ & $\begin{array}{c}0.131 * * * \\
(0.007)\end{array}$ \\
\hline EDUCAT. YEARS & $\begin{array}{l}-0.001 * \\
(0.001)\end{array}$ & & $\begin{array}{l}-0.001 * \\
(0.001)\end{array}$ \\
\hline MARRIED & $\begin{array}{c}0.027 * * * \\
(0.006)\end{array}$ & & $\begin{array}{c}0.026^{* * *} \\
(0.006)\end{array}$ \\
\hline WEALTH & $\begin{array}{c}0.103 * * * \\
(0.038)\end{array}$ & & $\begin{array}{c}0.103^{* * *} \\
(0.039)\end{array}$ \\
\hline Observations & 35,789 & 35,789 & 35,789 \\
\hline R-squared & 0.078 & 0.077 & 0.079 \\
\hline MinP-MinC & 0.0333 & 0.0326 & 0.0326 \\
\hline se MinP-MinC & 0.0102 & 0.0103 & 0.0103 \\
\hline pval MinP-MinC & 0.00132 & 0.00172 & 0.00172 \\
\hline MajP-MajC & 0.0164 & 0.0166 & 0.0118 \\
\hline se MajP-MajC & 0.0165 & 0.0164 & 0.0159 \\
\hline pval MajP-MajC & 0.321 & 0.311 & 0.460 \\
\hline
\end{tabular}

Robust standard errors in parentheses. ${ }^{* * *} \mathrm{p}<0.01, * * \mathrm{p}<0.05, * \mathrm{p}<0.1$.

Note: differential effect of being minority protestant compared to minority catholic, on the propensity of being an entrepreneur. Column 1 is the baseline model, column 2 excludes potentially endogenous variables, column 3 include regional controls (unemployment rate, GDP growth, the extent of motor ways, population density, number of doctors per thousand residents, proportion of graduated residents). All columns are estimated by linear probability model and include country and time fixed effects. Standard errors are clustered at the regional level. Controls include whether respondent is foreign national, age, gender, whether father was self-employed, years of education, whether respondent is married and whether main source of income is financial. 
Table 5 - Panel B Religious denomination and the propensity of being entrepreneur: robustness checks.

\begin{tabular}{|c|c|c|c|c|c|}
\hline VARIABLES & $\begin{array}{c}(1) \\
\text { selfemplACT }\end{array}$ & $\begin{array}{c}(2) \\
\text { selfemplACT }\end{array}$ & $\begin{array}{c}(3) \\
\text { selfemplACT }\end{array}$ & $\begin{array}{c}(4) \\
\text { selfemplACT }\end{array}$ & $\begin{array}{c}5) \\
\text { selfemplEMP }\end{array}$ \\
\hline PROTESTANT & $\begin{array}{l}-0.002 \\
(0.009)\end{array}$ & $\begin{array}{l}-0.003 \\
(0.008)\end{array}$ & $\begin{array}{l}-0.002 \\
(0.008)\end{array}$ & $\begin{array}{l}-0.003 \\
(0.008)\end{array}$ & $\begin{array}{l}-0.003 \\
(0.008)\end{array}$ \\
\hline MINORITY & $\begin{array}{c}0.007 \\
(0.028)\end{array}$ & $\begin{array}{c}0.006 \\
(0.012)\end{array}$ & $\begin{array}{c}0.008 \\
(0.013)\end{array}$ & $\begin{array}{c}0.005 \\
(0.012)\end{array}$ & $\begin{array}{c}0.007 \\
(0.013)\end{array}$ \\
\hline MAJORITY & $\begin{array}{c}0.001 \\
(0.011)\end{array}$ & $\begin{array}{l}-0.002 \\
(0.010)\end{array}$ & $\begin{array}{l}-0.009 \\
(0.013)\end{array}$ & $\begin{array}{c}0.001 \\
(0.011)\end{array}$ & $\begin{array}{l}-0.001 \\
(0.011)\end{array}$ \\
\hline PROTESTANT*MAJ. & $\begin{array}{c}0.016 \\
(0.015)\end{array}$ & $\begin{array}{c}0.026 \\
(0.016)\end{array}$ & $\begin{array}{c}0.125 \\
(0.089)\end{array}$ & $\begin{array}{c}0.015 \\
(0.015)\end{array}$ & $\begin{array}{c}0.016 \\
(0.016)\end{array}$ \\
\hline PROTESTANT*MIN. & $\begin{array}{c}0.035^{* * *} \\
(0.013)\end{array}$ & $\begin{array}{c}0.036 * * * \\
(0.011)\end{array}$ & $\begin{array}{c}0.038^{* * *} \\
(0.013)\end{array}$ & $\begin{array}{c}0.039 * * * \\
(0.012)\end{array}$ & $\begin{array}{c}0.036^{* * *} \\
(0.012)\end{array}$ \\
\hline FOREIGN & $\begin{array}{l}-0.015 \\
(0.016)\end{array}$ & $\begin{array}{l}-0.015 \\
(0.016)\end{array}$ & $\begin{array}{l}-0.017 \\
(0.016)\end{array}$ & $\begin{array}{l}-0.017 \\
(0.016)\end{array}$ & $\begin{array}{l}-0.020 \\
(0.017)\end{array}$ \\
\hline AGE & $\begin{array}{c}0.004 * * * \\
(0.000)\end{array}$ & $\begin{array}{c}0.004^{* * * *} \\
(0.000)\end{array}$ & $\begin{array}{c}0.004^{* * * *} \\
(0.000)\end{array}$ & $\begin{array}{c}0.004 * * * \\
(0.000)\end{array}$ & $\begin{array}{c}0.004 * * * \\
(0.000)\end{array}$ \\
\hline MALE & $\begin{array}{c}0.087 * * * \\
(0.007)\end{array}$ & $\begin{array}{c}0.086^{* * *} \\
(0.007)\end{array}$ & $\begin{array}{c}0.086^{* * * *} \\
(0.006)\end{array}$ & $\begin{array}{c}0.086 * * * \\
(0.007)\end{array}$ & $\begin{array}{c}0.088^{* * *} \\
(0.007)\end{array}$ \\
\hline FATHER SELF EMP. & $\begin{array}{c}0.130 * * * \\
(0.007)\end{array}$ & $\begin{array}{c}0.128 * * * \\
(0.007)\end{array}$ & $\begin{array}{c}0.132 * * * \\
(0.007)\end{array}$ & $\begin{array}{c}0.132^{* * * *} \\
(0.007)\end{array}$ & $\begin{array}{c}0.134 * * * \\
(0.007)\end{array}$ \\
\hline EDUCAT. YEARS & $\begin{array}{l}-0.001 \\
(0.001)\end{array}$ & $\begin{array}{l}-0.001 \\
(0.001)\end{array}$ & $\begin{array}{l}-0.001 * \\
(0.001)\end{array}$ & $\begin{array}{l}-0.001 \\
(0.001)\end{array}$ & $\begin{array}{c}-0.002^{* *} \\
(0.001)\end{array}$ \\
\hline MARRIED & $\begin{array}{c}0.026^{* * * *} \\
(0.006)\end{array}$ & $\begin{array}{c}0.023 * * * \\
(0.007)\end{array}$ & $\begin{array}{c}0.027 * * * \\
(0.006)\end{array}$ & $\begin{array}{c}0.027 * * * \\
(0.006)\end{array}$ & $\begin{array}{c}0.023^{* * *} * \\
(0.006)\end{array}$ \\
\hline WEALTH & $\begin{array}{c}0.103 * * * \\
(0.038)\end{array}$ & $\begin{array}{c}0.084^{* *} \\
(0.040)\end{array}$ & $\begin{array}{c}0.100^{* * *} \\
(0.038)\end{array}$ & $\begin{array}{c}0.103 * * * \\
(0.038)\end{array}$ & $\begin{array}{c}0.148^{* * *} \\
(0.046)\end{array}$ \\
\hline Observations & 35,789 & 33,177 & 35,880 & 35,790 & 33,993 \\
\hline R-squared & 0.081 & 0.075 & 0.078 & 0.078 & 0.080 \\
\hline MinP-MinC & 0.0332 & 0.0332 & 0.0360 & 0.0360 & 0.0335 \\
\hline se MinP-MinC & 0.0106 & 0.0103 & 0.0114 & 0.0103 & 0.0108 \\
\hline pval MinP-MinC & 0.00203 & 0.00145 & 0.00185 & 0.000573 & 0.00225 \\
\hline MajP-MajC & 0.0137 & 0.0236 & 0.124 & 0.0122 & 0.0128 \\
\hline se MajP-MajC & 0.0168 & 0.0178 & 0.0883 & 0.0169 & 0.0177 \\
\hline pval MajP-MajC & 0.416 & 0.185 & 0.163 & 0.473 & 0.471 \\
\hline
\end{tabular}

Robust standard errors in parentheses. ${ }^{* * *} \mathrm{p}<0.01,{ }^{* *} \mathrm{p}<0.05,{ }^{*} \mathrm{p}<0.1$

Note: differential effect of being minority protestant compared to minority catholic, on the propensity of being an entrepreneur. Column 1 includes NUTS 1 regional fixed effects instead of country fixed effects, column 2 is estimated only on regions where both religions are represented, minorities in column 3 are identified at NUTS 1 regional level instead of NUTS 3 whenever possible, minorities in column 4 are identified at NUTS 2 regional level instead of NUTS 3 whenever possible, column 5 include employed individuals only instead of active. All columns are estimated by linear probability model and include country and time fixed effects. Standard errors are clustered at the regional level. Controls include whether respondent is foreign national, age, gender, whether father was self-employed, years of education, whether respondent is married and whether main source of income is financial. 
Table 6 - Panel A: Religious denomination and the propensity of being entrepreneur: robustness checks

\begin{tabular}{|c|c|c|c|c|}
\hline VARIABLES & $\begin{array}{c}(1) \\
\text { selfemplACT } \\
\end{array}$ & $\begin{array}{c}(2) \\
\text { selfemplACT } \\
\end{array}$ & $\begin{array}{c}\text { (3) } \\
\text { selfemplACT } \\
\end{array}$ & $\begin{array}{c}(4) \\
\text { selfemplACT } \\
\end{array}$ \\
\hline PROTESTANT & $\begin{array}{l}-0.002 \\
(0.008)\end{array}$ & $\begin{array}{l}-0.002 \\
(0.008)\end{array}$ & $\begin{array}{l}-0.001 \\
(0.008)\end{array}$ & $\begin{array}{l}-0.008 \\
(0.009)\end{array}$ \\
\hline MINORITY & $\begin{array}{c}0.006 \\
(0.012)\end{array}$ & $\begin{array}{c}0.006 \\
(0.012)\end{array}$ & $\begin{array}{c}0.005 \\
(0.012)\end{array}$ & $\begin{array}{c}0.016 \\
(0.013)\end{array}$ \\
\hline MAJORITY & $\begin{array}{l}-0.003 \\
(0.010)\end{array}$ & $\begin{array}{c}0.002 \\
(0.011)\end{array}$ & $\begin{array}{c}0.003 \\
(0.011)\end{array}$ & $\begin{array}{l}-0.010 \\
(0.009)\end{array}$ \\
\hline PROTESTANT*MAJ. & $\begin{array}{c}0.000 \\
(0.000)\end{array}$ & $\begin{array}{c}0.017 \\
(0.015)\end{array}$ & $\begin{array}{c}0.000 \\
(0.000)\end{array}$ & $\begin{array}{c}0.001 \\
(0.010)\end{array}$ \\
\hline PROTESTANT*MIN. & $\begin{array}{c}0.035^{* * * *} \\
(0.012)\end{array}$ & $\begin{array}{l}0.024^{* *} \\
(0.010)\end{array}$ & $\begin{array}{l}0.022^{* *} \\
(0.011)\end{array}$ & $\begin{array}{c}0.035^{* * * *} \\
(0.013)\end{array}$ \\
\hline FOREIGN & $\begin{array}{l}-0.018 \\
(0.016)\end{array}$ & $\begin{array}{l}-0.011 \\
(0.020)\end{array}$ & $\begin{array}{l}-0.011 \\
(0.020)\end{array}$ & $\begin{array}{c}0.082 \\
(0.062)\end{array}$ \\
\hline AGE & $\begin{array}{c}0.004^{* * *} \\
(0.000)\end{array}$ & $\begin{array}{c}0.003^{* * *} \\
(0.000)\end{array}$ & $\begin{array}{c}0.003^{* * *} \\
(0.000)\end{array}$ & $\begin{array}{c}0.004 * * * \\
(0.000)\end{array}$ \\
\hline MALE & $\begin{array}{c}0.086^{* * * *} \\
(0.008)\end{array}$ & $\begin{array}{c}0.080^{* * * *} \\
(0.005)\end{array}$ & $\begin{array}{c}0.075^{* * * *} \\
(0.007)\end{array}$ & $\begin{array}{c}0.088^{* * * *} \\
(0.007)\end{array}$ \\
\hline FATHER SELF EMP. & $\begin{array}{c}0.148^{* * * *} \\
(0.007)\end{array}$ & $\begin{array}{c}0.115^{* * * *} \\
(0.008)\end{array}$ & $\begin{array}{c}0.136^{* * * *} \\
(0.009)\end{array}$ & $\begin{array}{c}0.136^{* * *} \\
(0.007)\end{array}$ \\
\hline EDUCAT. YEARS & $\begin{array}{l}-0.000 \\
(0.001)\end{array}$ & $\begin{array}{c}0.001 \\
(0.001)\end{array}$ & $\begin{array}{c}0.004 * * * \\
(0.001)\end{array}$ & $\begin{array}{c}-0.002 * * * \\
(0.001)\end{array}$ \\
\hline MARRIED & $\begin{array}{c}0.027 * * * \\
(0.007)\end{array}$ & $\begin{array}{c}0.018^{* * *} \\
(0.006)\end{array}$ & $\begin{array}{l}0.015^{*} \\
(0.008)\end{array}$ & $\begin{array}{c}0.031 * * * \\
(0.006)\end{array}$ \\
\hline WEALTH & $\begin{array}{c}0.097 * * \\
(0.041)\end{array}$ & $\begin{array}{c}0.088^{* *} \\
(0.042)\end{array}$ & $\begin{array}{l}0.070^{*} \\
(0.040)\end{array}$ & $\begin{array}{c}0.105^{* *} \\
(0.043)\end{array}$ \\
\hline Observations & 28,497 & 24,586 & 17,294 & 32,191 \\
\hline R-squared & 0.082 & 0.059 & 0.063 & 0.081 \\
\hline MinP-MinC & 0.0333 & 0.0218 & 0.0209 & 0.0264 \\
\hline se MinP-MinC & 0.0103 & 0.00886 & 0.00895 & 0.0120 \\
\hline pval MinP-MinC & 0.00136 & 0.0150 & 0.0208 & 0.0287 \\
\hline MajP-MajC & -0.00151 & 0.0151 & -0.00106 & -0.00704 \\
\hline se MajP-MajC & 0.00792 & 0.0170 & 0.00825 & 0.0140 \\
\hline pval MajP-MajC & 0.849 & 0.376 & 0.898 & 0.615 \\
\hline
\end{tabular}

Robust standard errors in parentheses. ${ }^{* * *} \mathrm{p}<0.01,{ }^{* *} \mathrm{p}<0.05,{ }^{*} \mathrm{p}<0.1$

Note: differential effect of being minority protestant compared to minority catholic, on the propensity of being an entrepreneur. Column 1 excludes countries with predominant protestant majority (Norway, Sweden, Denmark, Finland), column 2 excludes countries with predominant catholic majority (Italy, Spain, Poland, Portugal, Ireland), column 3 excludes countries with both predominant protestant and catholic majority, column 4 excludes all first and second generation immigrants in estimation and calculation of minorities. All columns are estimated by linear probability model and include country and time fixed effects. Standard errors are clustered at the regional level. Controls include whether respondent is foreign national, age, gender, whether father was self-employed, years of education, whether respondent is married and whether main source of income is financial. 
Table 6 - Panel B: The differential effect of Protestantism by dropping one country at a time

\begin{tabular}{llll}
\hline country & MinP-MinC & s.e. & pval \\
\hline AT & 0.030 & 0.011 & 0.008 \\
BE & 0.033 & 0.010 & 0.002 \\
CH & 0.033 & 0.012 & 0.005 \\
CZ & 0.031 & 0.010 & 0.003 \\
DE & 0.033 & 0.011 & 0.004 \\
DK & 0.033 & 0.010 & 0.001 \\
EE & 0.033 & 0.010 & 0.001 \\
ES & 0.031 & 0.010 & 0.003 \\
FI & 0.033 & 0.010 & 0.001 \\
FR & 0.035 & 0.010 & 0.001 \\
GB & 0.033 & 0.010 & 0.002 \\
HU & 0.041 & 0.011 & 0.000 \\
IE & 0.029 & 0.010 & 0.004 \\
IT & 0.034 & 0.010 & 0.001 \\
LU & 0.032 & 0.010 & 0.002 \\
NL & 0.038 & 0.011 & 0.000 \\
NO & 0.033 & 0.010 & 0.001 \\
PL & 0.033 & 0.010 & 0.001 \\
PT & 0.029 & 0.009 & 0.002 \\
SE & 0.033 & 0.010 & 0.001 \\
SI & 0.033 & 0.010 & 0.001 \\
SK & 0.039 & 0.012 & 0.001 \\
& & & \\
Total Sample & 0.033 & 0.010 & 0.002 \\
\hline & & &
\end{tabular}

Note: The adopted specification is that of Table 5 Panel A col. 1 
Table 6 -Panel C: Religious denomination and the propensity of being entrepreneur: robustness checks

\begin{tabular}{lccc}
\hline VARIABLES & $\begin{array}{c}(1) \\
\text { Belong to a } \\
\text { discriminated group }\end{array}$ & $\begin{array}{c}(2) \\
\text { Discriminated for } \\
\text { religious reasons }\end{array}$ & $\begin{array}{c}(3) \\
\text { unportance } \\
\text { understand others }\end{array}$ \\
\hline PROTESTANT & $0.0142^{*}$ & $-0.0170^{* * *}$ & 0.0171 \\
MINORITY & $(0.00796)$ & $(0.00635)$ & $(0.0156)$ \\
& $0.0241^{* * *}$ & -0.0128 & 0.0176 \\
MAJORITY & $(0.00802)$ & $(0.00831)$ & $(0.0195)$ \\
& $0.0363^{* *}$ & $-0.0183^{* *}$ & 0.00127 \\
PROTESTANT * MIN & $(0.0142)$ & $(0.00900)$ & $(0.0122)$ \\
& $-0.0277^{*}$ & $0.0287^{* *}$ & -0.00361 \\
PROTESTANT * MAJ & $(0.0142)$ & $(0.0126)$ & $(0.0229)$ \\
& $-0.0333^{* *}$ & $0.0224^{* *}$ & -0.00712 \\
Observations & $(0.0160)$ & $(0.0101)$ & $(0.0227)$ \\
R-squared & & & 66361 \\
MinP-MinC & 69703 & 70844 & 0.041 \\
se MinP-MinC & 0.028 & 0.022 & 0.0135 \\
pval MinP-MinC & -0.0135 & 0.0117 & 0.0191 \\
MajP-MajC & 0.00971 & 0.00859 & 0.479 \\
se MajP-MajC & 0.165 & 0.175 & 0.01000 \\
pval MajP-MajC & -0.0191 & 0.00547 & 0.0209 \\
\hline
\end{tabular}

Note: Sample composed by both the active and the inactive. First and second generation immigrants excluded. Country dummies are included. 
Table 6 - Panel D: Religious denomination and the propensity of being entrepreneur: robustness checks

\begin{tabular}{|c|c|c|c|}
\hline VARIABLES & $\begin{array}{c}(1) \\
\text { selfemplACT }\end{array}$ & $\begin{array}{c}(2) \\
\text { selfemplACT }\end{array}$ & $\begin{array}{c}(3) \\
\text { selfemplACT }\end{array}$ \\
\hline PROTESTANT & $\begin{array}{l}-0.005 \\
(0.007)\end{array}$ & $\begin{array}{l}-0.005 \\
(0.006)\end{array}$ & $\begin{array}{l}-0.002 \\
(0.008)\end{array}$ \\
\hline MINORITY & $\begin{array}{c}0.001 \\
(0.011)\end{array}$ & $\begin{array}{c}0.012 \\
(0.011)\end{array}$ & $\begin{array}{c}0.006 \\
(0.012)\end{array}$ \\
\hline MAJORITY & $\begin{array}{l}-0.003 \\
(0.009)\end{array}$ & $\begin{array}{l}-0.005 \\
(0.011)\end{array}$ & $\begin{array}{l}-0.003 \\
(0.010)\end{array}$ \\
\hline PROTESTANT*MAJ. & $\begin{array}{c}0.015 \\
(0.014)\end{array}$ & $\begin{array}{c}0.014 \\
(0.018)\end{array}$ & $\begin{array}{c}0.020 \\
(0.015)\end{array}$ \\
\hline PROTESTANT*MIN. & $\begin{array}{c}0.030^{* * * *} \\
(0.010)\end{array}$ & $\begin{array}{c}0.033^{* * *} \\
(0.011)\end{array}$ & $\begin{array}{c}0.034 * * * \\
(0.012)\end{array}$ \\
\hline FOREIGN & $\begin{array}{c}-0.028^{* *} \\
(0.014)\end{array}$ & $\begin{array}{c}0.001 \\
(0.013)\end{array}$ & $\begin{array}{l}-0.018 \\
(0.016)\end{array}$ \\
\hline AGE & $\begin{array}{c}0.004 * * * \\
(0.000)\end{array}$ & $\begin{array}{c}0.003^{* * *} \\
(0.000)\end{array}$ & $\begin{array}{c}0.004 * * * \\
(0.000)\end{array}$ \\
\hline MALE & $\begin{array}{c}0.066^{* * *} \\
(0.005)\end{array}$ & $\begin{array}{c}0.071^{* * *} \\
(0.005)\end{array}$ & $\begin{array}{c}0.087^{* * * *} \\
(0.007)\end{array}$ \\
\hline FATHER SELF EMP. & $\begin{array}{c}0.089^{* * * *} \\
(0.006)\end{array}$ & $\begin{array}{c}0.076^{* * *} \\
(0.006)\end{array}$ & $\begin{array}{c}0.137 * * * \\
(0.007)\end{array}$ \\
\hline EDUCAT. YEARS & $\begin{array}{c}0.004 * * * \\
(0.001)\end{array}$ & $\begin{array}{c}0.002^{* *} \\
(0.001)\end{array}$ & $\begin{array}{l}-0.001 * \\
(0.001)\end{array}$ \\
\hline MARRIED & $\begin{array}{c}0.030^{* * *} \\
(0.006)\end{array}$ & $\begin{array}{c}0.024^{* * *} \\
(0.006)\end{array}$ & $\begin{array}{c}0.027^{* * *} \\
(0.006)\end{array}$ \\
\hline WEALTH & $\begin{array}{c}0.077^{* *} \\
(0.035)\end{array}$ & $\begin{array}{c}0.104 * * * \\
(0.034)\end{array}$ & $\begin{array}{c}0.103^{* * *} \\
(0.039)\end{array}$ \\
\hline Observations & 35,789 & 34,174 & 35,360 \\
\hline R-squared & 0.171 & 0.053 & 0.081 \\
\hline MinP-MinC & 0.0247 & 0.0273 & 0.0322 \\
\hline se MinP-MinC & 0.00962 & 0.0103 & 0.0104 \\
\hline pval MinP-MinC & 0.0110 & 0.00864 & 0.00226 \\
\hline MajP-MajC & 0.00981 & 0.00852 & 0.0178 \\
\hline se MajP-MajC & 0.0149 & 0.0187 & 0.0168 \\
\hline pval MajP-MajC & 0.512 & 0.649 & 0.291 \\
\hline
\end{tabular}

Robust standard errors in parentheses. ${ }^{* * *} \mathrm{p}<0.01,{ }^{* *} \mathrm{p}<0.05,{ }^{*} \mathrm{p}<0.1$

Note: differential effect of being minority protestant compared to minority catholic, on the propensity of being an entrepreneur. Column 1 controls for sectoral composition at regional level, column 2 excludes individuals whose main activity is agriculture, column 3 excludes unpaid family workers. All columns are estimated by linear probability model and include country and time fixed effects. Standard errors are clustered at the regional level. Controls include whether respondent is foreign national, age, gender, whether father was self-employed, years of education, whether respondent is married and whether main source of income is financial. 
Table A1: religious minorities and social networks

\begin{tabular}{|c|c|c|c|c|c|c|c|c|c|c|c|}
\hline & $\begin{array}{c}\text { (1) } \\
\mathrm{n} . \\
\text { friend } \\
\mathrm{s} \\
\text { workp } \\
\text { lace }\end{array}$ & $\begin{array}{c}\text { (2) } \\
\text { n. } \\
\text { friends } \\
\text { neighbor } \\
\text { hood }\end{array}$ & $\begin{array}{c}\text { (3) } \\
\text { n. } \\
\text { friends } \\
\text { associat } \\
\text { ions }\end{array}$ & $\begin{array}{c}(4) \\
\text { particip } \\
\text { ate } \\
\text { volunta } \\
\text { ry } \\
\text { associat } \\
\text { ions }\end{array}$ & $\begin{array}{l}(5) \\
\text { borro } \\
\mathrm{w} \\
\text { from } \\
\text { frien } \\
\mathrm{ds} \\
\text { relati } \\
\text { ves }\end{array}$ & $\begin{array}{c}(6) \\
\text { helpe } \\
\mathrm{d} \\
\text { outsi } \\
\text { de } \\
\text { famil } \\
y\end{array}$ & $\begin{array}{l}\text { (7) } \\
\text { lend } \\
\text { to } \\
\text { frien } \\
\text { ds } \\
\text { relati } \\
\text { ves }\end{array}$ & $\begin{array}{l}\text { (8) } \\
\text { help } \\
\text { ed } \\
\text { s.o. } \\
\text { find } \\
\text { a job }\end{array}$ & $\begin{array}{c}(9) \\
\text { work } \\
\text { informa } \\
\text { tion } \\
\text { from } \\
\text { friends } \\
\text { relative } \\
\text { s }\end{array}$ & $\begin{array}{c}(10) \\
\text { compl } \\
\text { etely } \\
\text { trust } \\
\text { many } \\
\text { people }\end{array}$ & $\begin{array}{l}\text { (11) } \\
\text { others } \\
\text { take } \\
\text { advant } \\
\text { age } \\
\text { of you }\end{array}$ \\
\hline $\begin{array}{l}\text { Protesta } \\
\text { nt }\end{array}$ & -0.095 & -0.181 & -0.490 & 0.032 & 0.014 & 0.023 & $\begin{array}{c}- \\
0.014\end{array}$ & $\begin{array}{c}0.05 \\
6 * *\end{array}$ & 0.028 & 0.014 & $\begin{array}{c}- \\
0.070 * \\
* *\end{array}$ \\
\hline & $\begin{array}{c}(0.225 \\
)\end{array}$ & (0.198) & $(0.477)$ & $(0.026)$ & $\begin{array}{c}(0.02 \\
6)\end{array}$ & $\begin{array}{c}(0.02 \\
6)\end{array}$ & $\begin{array}{c}(0.02 \\
4)\end{array}$ & $\begin{array}{c}(0.02 \\
7)\end{array}$ & $(0.028)$ & $(0.019)$ & $\begin{array}{c}(0.026 \\
)\end{array}$ \\
\hline Minority & 0.327 & -0.475 & $-1.148^{*}$ & -0.033 & 0.019 & 0.054 & 0.080 & $\begin{array}{c}- \\
0.01 \\
3\end{array}$ & 0.020 & 0.045 & -0.072 \\
\hline & $\begin{array}{c}(0.339 \\
)\end{array}$ & $(0.319)$ & $(0.678)$ & $(0.055)$ & $\begin{array}{c}(0.05 \\
7)\end{array}$ & $\begin{array}{c}(0.05 \\
7)\end{array}$ & $\begin{array}{c}(0.05 \\
3)\end{array}$ & $\begin{array}{c}(0.05 \\
4)\end{array}$ & $(0.061)$ & $(0.040)$ & $\begin{array}{c}(0.060 \\
)\end{array}$ \\
\hline $\begin{array}{l}\text { Minority } \\
\text { Protesta } \\
\text { nt }\end{array}$ & 2.113 & 0.249 & 3.177 & 0.109 & 0.080 & 0.023 & 0.133 & $\begin{array}{c}0.03 \\
5\end{array}$ & -0.130 & -0.051 & 0.064 \\
\hline & $\begin{array}{c}(1.657 \\
)\end{array}$ & $(0.726)$ & $(2.161)$ & $(0.097)$ & $\begin{array}{c}(0.09 \\
5)\end{array}$ & $\begin{array}{c}(0.09 \\
2)\end{array}$ & $\begin{array}{c}(0.09 \\
2)\end{array}$ & $\begin{array}{c}(0.09 \\
5)\end{array}$ & $(0.106)$ & $(0.068)$ & $\begin{array}{c}(0.098 \\
)\end{array}$ \\
\hline $\begin{array}{l}\text { Constan } \\
\mathrm{t}\end{array}$ & $\begin{array}{c}1.940 * \\
* \\
(0.901 \\
)\end{array}$ & $\begin{array}{c}4.776^{* * *} \\
(0.873)\end{array}$ & $\begin{array}{c}10.683 * \\
* * \\
(1.503)\end{array}$ & $\begin{array}{c}0.396^{* *} \\
* \\
(0.080)\end{array}$ & $\begin{array}{c}1.206 \\
* * * \\
(0.07 \\
5)\end{array}$ & $\begin{array}{c}0.549 \\
* * * \\
(0.07 \\
9)\end{array}$ & $\begin{array}{c}0.439 \\
* * * \\
(0.07 \\
7)\end{array}$ & $\begin{array}{c}0.07 \\
2 \\
(0.07 \\
9)\end{array}$ & $\begin{array}{c}0.684 * * \\
* \\
(0.093)\end{array}$ & $\begin{array}{c}0.087 \\
(0.063)\end{array}$ & $\begin{array}{c}1.122 * \\
* * \\
(0.071 \\
)\end{array}$ \\
\hline $\begin{array}{l}\text { Observa } \\
\text { tions }\end{array}$ & 4,588 & 6,354 & 6,525 & 6,693 & 6,590 & 6,558 & 6,477 & $\begin{array}{c}6,48 \\
0\end{array}$ & 5,937 & 6,593 & 6,483 \\
\hline $\begin{array}{l}\mathrm{R} \text { - } \\
\text { squared }\end{array}$ & 0.118 & 0.072 & 0.085 & 0.216 & 0.108 & 0.070 & 0.056 & $\begin{array}{c}0.10 \\
0\end{array}$ & 0.068 & 0.053 & 0.211 \\
\hline
\end{tabular}

Note: Based on ISSP survey Social Networks II. OLS estimates of equation (1) where minority catholic is replaced by minority (= minority catholic + minority protestant). The estimate associated to minority indicates the common differential impact of belonging to a protestant or catholic minority. The estimate associated to minority protestant indicates the differential impact between minorities. Only individuals in their working age (15-70) are included. Robust standard errors in parentheses $* * * \mathrm{p}<0.01, * * \mathrm{p}<0.05,{ }^{*} \mathrm{p}<0.1$.

Regions used to determine minorities are as disaggregated as NUTS 2 whenever possible, excepting for Latvia (NUTS 3) due to the large sample size available in this survey and due to the fact that NUTS 2 is not defined for Latvia. All specification include: gender, age, years of education, urban or rural residence, marital status, number of siblings, number children under 18, number of adult sons/daughters, years of residence in the current place, a dummy for the Latvian region of Latgale (NUTS 3) and regional (NUTS 1) fixed effects. Countries included: Germany, UK, Austria, Hungary, Norway, Slovenia, Poland, Spain, Latvia, France, Denmark, Switzerland, Finland. Number of regions: 109. 
Table B1. European Social Survey, Participating Countries and Sample Size

\begin{tabular}{|c|c|c|c|c|c|}
\hline \multicolumn{6}{|c|}{ ESS Round } \\
\hline country & 1 & 2 & 3 & 4 & Total \\
\hline AT & 2,257 & 2,256 & 2,405 & & 6,918 \\
\hline $\mathrm{BE}$ & 1,899 & 1,778 & 1,798 & 1,760 & 7,235 \\
\hline $\mathrm{CH}$ & 2,040 & 2,141 & 1,804 & 1,819 & 7,804 \\
\hline $\mathrm{CZ}$ & 1,360 & 3,026 & & & 4,386 \\
\hline $\mathrm{DE}$ & 2,919 & 2,870 & 2,916 & 2,751 & 11,456 \\
\hline $\mathrm{DK}$ & 1,506 & 1,487 & 1,505 & 1,610 & 6,108 \\
\hline EE & & 1,989 & 1,517 & 1,661 & 5,167 \\
\hline ES & 1,729 & 1,663 & 1,876 & 2,576 & 7,844 \\
\hline FI & 2,000 & 2,022 & 1,896 & 2,195 & 8,113 \\
\hline FR & 1,503 & 1,806 & 1,986 & 2,073 & 7,368 \\
\hline GB & 2,052 & 1,897 & 2,394 & 2,352 & 8,695 \\
\hline $\mathrm{HU}$ & 1,685 & 1,498 & 1,518 & 1,544 & 6,245 \\
\hline IE & 2,046 & 2,286 & 1,800 & & 6,132 \\
\hline IT & 1,207 & 1,529 & & & 2,736 \\
\hline $\mathrm{LU}$ & 1,552 & 1,635 & & & 3,187 \\
\hline NL & 2,364 & 1,881 & 1,889 & 1,778 & 7,912 \\
\hline $\mathrm{NO}$ & 2,036 & 1,760 & 1,750 & 1,549 & 7,095 \\
\hline PL & 2,110 & 1,716 & 1,721 & 1,619 & 7,166 \\
\hline PT & 1,511 & 2,052 & 2,222 & 2,367 & 8,152 \\
\hline SE & 1,999 & 1,948 & 1,927 & 1,830 & 7,704 \\
\hline SI & 1,519 & 1,442 & 1,476 & 1,286 & 5,723 \\
\hline SK & & 1,512 & 1,766 & 1,810 & 5,088 \\
\hline Total & 37,294 & 42,194 & 36,166 & 32,580 & 148,234 \\
\hline
\end{tabular}

Note: only countries in our sample are reported, i.e. we exclude orthodox countries and Israel from original ESS sample. 
Table B2: Summary statistics of regional controls

\begin{tabular}{|c|c|c|c|c|c|c|}
\hline country & $\begin{array}{l}\text { unemployment rate } \\
\text { (pop. aged 15-64) }\end{array}$ & $\begin{array}{l}\text { motorways } \\
(\mathrm{km})\end{array}$ & $\begin{array}{c}\text { population } \\
\text { density } \\
(\text { per km²) }\end{array}$ & $\begin{array}{c}\text { number } \\
\text { of doctors } \\
\text { per } 100 \mathrm{k} \\
\text { residents }\end{array}$ & $\begin{array}{l}\text { regional } \\
\text { gdp } \\
\text { growth } \\
\text { rate }\end{array}$ & $\begin{array}{l}\text { proportion } \\
\text { graduate } \\
\text { residents }\end{array}$ \\
\hline AT & 4.51 & 37.39 & 848.67 & 346.60 & 2.08 & 0.17 \\
\hline $\mathrm{BE}$ & 7.44 & 60.06 & 694.96 & 389.33 & 2.52 & 0.30 \\
\hline $\mathrm{CH}$ & 4.17 & 41.50 & 283.39 & 367.49 & 1.70 & 0.31 \\
\hline $\mathrm{CZ}$ & 8.03 & 7.90 & 369.89 & 350.44 & 8.81 & 0.12 \\
\hline $\mathrm{DE}$ & 11.00 & 41.48 & 512.23 & 337.19 & 1.62 & 0.25 \\
\hline DK & 3.64 & 33.15 & 228.74 & 309.83 & 2.90 & 0.31 \\
\hline $\mathrm{EE}$ & 7.01 & 2.29 & 55.88 & 322.01 & 13.29 & 0.33 \\
\hline ES & 10.58 & 35.52 & 209.43 & 344.96 & 4.01 & 0.27 \\
\hline FI & 7.76 & 6.68 & 39.97 & 307.92 & 3.63 & 0.35 \\
\hline FR & 8.30 & 25.41 & 230.40 & 333.38 & 2.45 & 0.25 \\
\hline GB & 5.17 & 22.82 & 642.83 & 231.35 & 3.51 & 0.28 \\
\hline $\mathrm{HU}$ & 7.18 & 14.00 & 165.17 & 312.56 & 5.03 & 0.16 \\
\hline IE & 4.47 & 3.24 & 69.21 & 268.67 & 5.33 & 0.27 \\
\hline IT & 9.64 & 25.10 & 240.31 & 504.59 & 0.72 & 0.11 \\
\hline $\mathrm{LU}$ & 3.90 & 52.76 & 174.89 & 280.53 & 4.52 & 0.21 \\
\hline NL & 3.55 & 90.33 & 774.50 & 319.18 & 3.68 & 0.28 \\
\hline $\mathrm{NO}$ & 3.53 & 5.48 & 58.02 & 344.90 & 6.39 & 0.33 \\
\hline PL & 15.34 & 2.22 & 154.91 & 225.06 & 5.90 & 0.16 \\
\hline PT & 6.97 & 94.22 & 430.54 & 289.37 & 1.46 & 0.13 \\
\hline SE & 6.13 & 20.18 & 88.77 & 342.02 & 3.29 & 0.29 \\
\hline SI & 5.95 & 29.27 & 121.03 & 227.56 & 5.38 & 0.22 \\
\hline SK & 13.67 & 10.77 & 126.85 & 321.06 & 13.73 & 0.14 \\
\hline Average & 7.25 & 31.29 & 322.93 & 318.73 & 4.30 & 0.25 \\
\hline
\end{tabular}


Table C1: Coefficients associated to SOEP measures of risk aversion for both Catholic and Protestant outcomes.

\begin{tabular}{lcccl}
\hline & Religious & Catholic & Protestant & difference \\
RRA & -0.011 & -0.020 & -.0208 & 0.00 \\
p value & 0.249 & 0.196 & 0.129 & 0.997 \\
willingness & 0.029 & 0.043 & 0.034 & 0.99 \\
p value & 0.000 & 0.000 & 0.000 & 0.319 \\
\hline
\end{tabular}

Note: RRA is relative risk aversion; willingness is willingness to take risks ( 0 is the maximum level and 10 the lowest level). Column (1): Probit model estimates based on SOEP 2004. Religious takes on 1 for Catholics or Protestants and 0 for atheists. Controls are lander dummies, age, gender, years of education, marital status, employment condition, and father and mother religion. Furthermore, we have tested whether the degree of risk aversion is correlated with the particular individual confession. Column (2) and (3): multinomial probit model estimates based on SOEP 2004 data. The dependent variable is individual confession (Atheist - the baseline outcome - , Catholic and Protestant). Same controls as in Column (1). Column (4): difference between (2) and (3). 